\title{
A Review of the Flow-Induced Noise Study for Centrifugal Pumps
}

\author{
Chang Guo, Ming Gao * ${ }^{-1}$ and Suoying He \\ School of Energy and Power Engineering, Shandong University, Jinan 250061, China; gg3263@163.com (C.G.); \\ suoyinghe@hotmail.com (S.H.) \\ * Correspondence: gm@sdu.edu.cn; Tel.: +86-88399008
}

Received: 20 December 2019; Accepted: 1 February 2020; Published: 4 February 2020

check for updates

\begin{abstract}
Flow-induced noise is a significant concern for the design and operation of centrifugal pumps. The negative impacts of flow-induced noise on operating stability, human health and the environment have been shown in many cases. This paper presents a comprehensive review of the flow-induced noise study for centrifugal pumps to synthesize the current study status. First, the generation mechanism and propagation route of flow-induced noise are discussed. Then, three kinds of study methodologies, including the theoretical study of hydrodynamic noise, numerical simulation and experimental measurement study, are summarized. Subsequently, the application of the three study methodologies to the analysis of the distribution characteristics of flow-induced noise is analyzed from aspects of the noise source identification and comparison, the frequency response analysis, the directivity characteristics of sound field and the noise changing characteristics under various operating conditions. After that, the analysis of the noise optimization design of centrifugal pumps is summarized. Finally, based on previous study results, this paper puts forward the unsolved problems and implications for future study. In conclusion, the information collected in this review paper could guide further study of the flow-induced noise of centrifugal pumps.
\end{abstract}

Keywords: centrifugal pump; flow-induced noise; theoretical study; numerical simulation; experimental measurement; noise optimization design

\section{Introduction}

With the development of science and technology, as well as the community's increased awareness of the human impact on the environment, the effect of noise pollution has become more prominent. Noise data statistics, analysis and control strategy in different fields have attracted interest in different countries and regions [1-6]. According to the report issued by the Ministry of the ecological environment in China, the contribution to the overall environmental pollution by noise exceeded $30 \%$ in 2018 , coming in second place only to air pollution [1]. The negative impacts of noise on human health have attracted widespread attention [3,7-9]. The report issued by the World Health Organization (WHO) in 2018 revealed that the burden of disease from environmental noise was the second highest [3], which also reflects the seriousness of noise pollution.

As major energy conversion devices, the centrifugal pumps have been gradually applied in the fields of industry, agriculture, transportation and architecture and so forth. Due to the complexity of flow inside pumps, severe flow-induced noise is generated. For instance, the noise generated by a $22 \mathrm{~kW}$ single-stage single-suction centrifugal pump in air and water medium is up to $94 \mathrm{~dB}$ and $180 \mathrm{~dB}$ at rated operating conditions, respectively, both of which are much higher than the international standard [10]. The unexpected high-level noise could affect the operating stability, living and working environment and human health. Therefore, the study of flow-induced noise generated by centrifugal 
pumps is extremely significant from the perspective of engineering, environmental protection and human health.

A large amount of studies have been conducted on this subject and many have been discovered in the past decades. For example, according to Web of Science, more than 130 articles, as shown in Figure 1, analyzed the subject directly in terms of the generation mechanism and propagation route, the distribution characteristics and the optimization design of flow-induced noise which are based on theoretical analysis, numerical simulation and experimental measurement, let alone the number of articles that are indirectly related to the subject. The purpose of this paper is to summarize the study progress and corresponding valuable conclusions systematically. Then, the areas that may need to be paid attention to are emphasized, which could lay a foundation for further study.

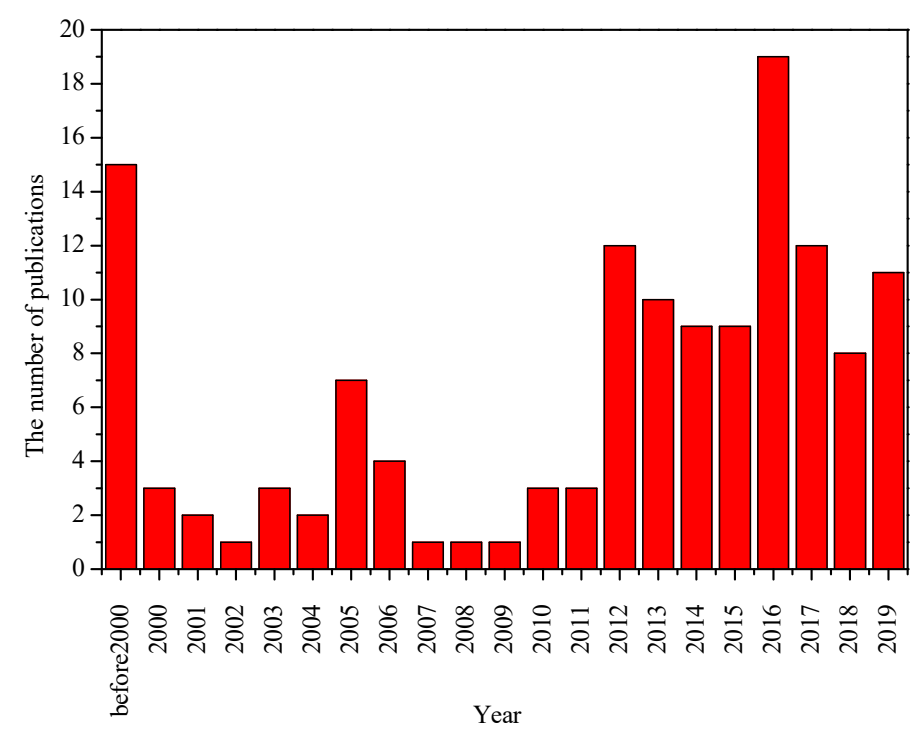

Figure 1. Paper publication information related directly to flow-induced noise of centrifugal pumps.

\section{The Generation Mechanism and Propagation Route of Flow-Induced Noise}

Flow-induced noise, which is related to various complex phenomena inside pumps, plays a crucial role in the noise level evaluation of centrifugal pumps with good structural design and stable installation [11]. Table 1 summarizes the different flow phenomena and noise generation mechanisms.

To evaluate the noise level generated by the above phenomena, the most widely used standard is the sound pressure level (SPL) and total sound pressure level (TSPL). SPL and TSPL are defined as,

$$
\begin{gathered}
S P L=20 \lg \frac{P_{e}}{P_{\text {ref }}} \\
T P S L=10 \lg \sum_{i=1}^{n} 10^{S P L_{i} / 10},
\end{gathered}
$$

where $P_{\text {ref }}$ is the reference sound pressure $\left(2 \times 10^{-5} \mathrm{~Pa}\right.$ in air, $1 \times 10^{-6} \mathrm{~Pa}$ in water $), n$ is the number of frequencies, $P_{e}$ is the effective sound pressure and it is defined as,

$$
P_{e}=\sqrt{\frac{1}{T}} \int_{0}^{T} p^{\prime 2} d t
$$

where $p^{\prime}$ is the instantaneous sound pressure, $T$ represents several rotational periods.

In addition, other parameters used for noise level evaluation, such as the sound power level and sound energy density [25], could be calculated from the SPL and TSPL, which are not discussed here. 
Currently, analysis of the noise induced by rotor-stator interaction and cavitation accounts for the majority.

Table 1. Complex flow phenomena and flow-induced noise generation mechanism.

\begin{tabular}{ccc}
\hline Flow Phenomena & References & Noise Generation Mechanism \\
\hline $\begin{array}{l}\text { Rotor-stator } \\
\text { interaction }\end{array}$ & {$[12-14]$} & $\begin{array}{c}\text { Periodic interference occurs between blade and volute. The flow } \\
\text { passage width changes periodically, which causes periodic } \\
\text { pressure fluctuations and noise. }\end{array}$ \\
\hline Cavitation & {$[15-17]$} & $\begin{array}{r}\text { The generated-bubbles due to cavitation implode in contact with } \\
\text { solid surface in high pressure region, which induce pressure } \\
\text { waves that result in the generation of noise. }\end{array}$ \\
\hline Turbulence & {$[18,19]$} & $\begin{array}{c}\text { Combined with the jet-wake effect at impeller outlet, the } \\
\text { interaction between blade and high-speed fluid causes the blade } \\
\text { acted by the unsteady load continuously and broadband noise } \\
\text { is generated. }\end{array}$ \\
\hline Back flow & {$[20]$} & $\begin{array}{c}\text { Pre-rotation occurs at impeller inlet, strong eddy and eddy strip } \\
\text { are formed. Then pressure fluctuations with low frequency are } \\
\text { generated and further induce the low frequency noise. }\end{array}$ \\
\hline Rotating stall & {$[21,22]$} & $\begin{array}{c}\text { Under low flow rate condition, stall vortex is formed in impeller, } \\
\text { which blocks the flow passage and induces low frequency noise. }\end{array}$ \\
\hline Water hammer & {$[23,24]$} & $\begin{array}{r}\text { Rapid change of flow velocity occurs, which could induce } \\
\text { intermittent noise. }\end{array}$ \\
\hline
\end{tabular}

\section{(1) Rotor-stator interaction}

In the process of fluid motion, the physical quantities, such as pressure, velocity and vorticity, at a certain spatial point inside pumps fluctuate rapidly once as a blade passes. With blades continuously rotating, the physical quantities fluctuate periodically [26], that is, the rotor-stator interaction effect exists in whole pumps. As the main cause of flow-induced noise, the rotor-stator interaction could cause the frequency response characteristics of flow-induced noise at different monitoring points that are dominated by characteristic frequencies such as the blade-passing frequency $\left(f_{b}\right)$ and its harmonic frequencies in a low frequency band. As shown in Figure 2, the SPL reaches to peak at $290 \mathrm{~Hz}\left(f_{b}\right)$ and its high order harmonics and also shows a trend of fluctuating downward.

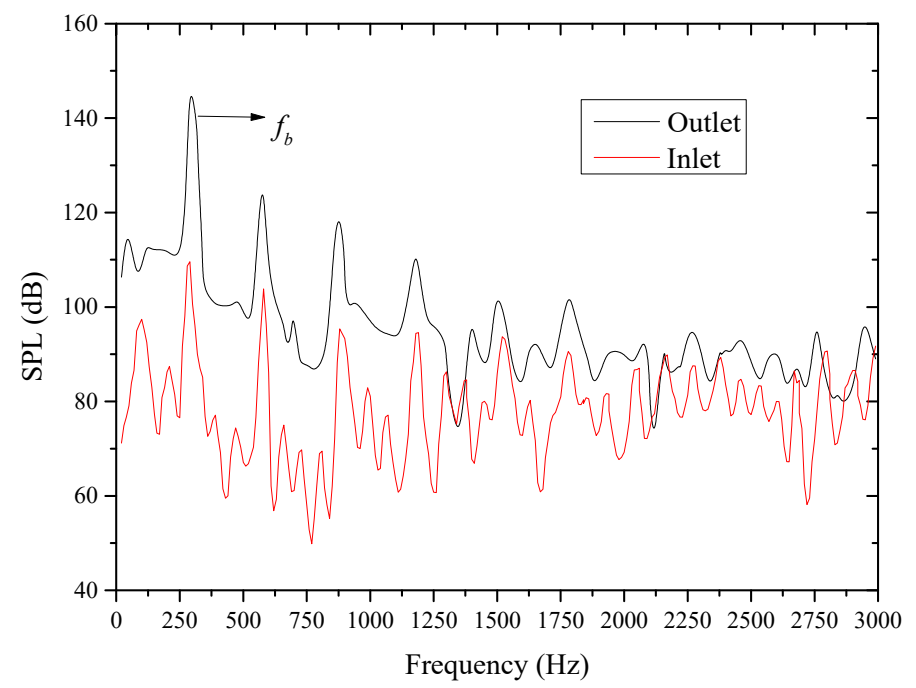

Figure 2. Frequency response characteristics of noise induced by rotor-stator interaction at inlet and outlet pipes [27]. 


\section{(2) Cavitation}

Different from the noise induced by rotor-stator interaction, the noise induced by cavitation is a kind of broadband noise and concentrates in a high frequency band [28]. During the cavitation inception stage, the noise level decreases slightly in the broadband band [29]. With the decrease of the available net positive suction head (NPSHa), the periodic fluctuations characteristics of sound pressure disappear gradually and the sound pressure intensity at inlet and outlet pipes decreases and increases, respectively [30]. Figure 3 shows the frequency response characteristics of power spectral density (PSD) signal of sound pressure at the outlet pipe. With the decrease of NPSHa, the frequency response characteristics that are dominated by characteristic frequencies weaken gradually in low frequency band, which means that the cavitation could inhibit the rotor-stator interaction to some extent [31]. When the frequency is higher than $1000 \mathrm{~Hz}$, the PSD signal oscillation intensifies significantly.

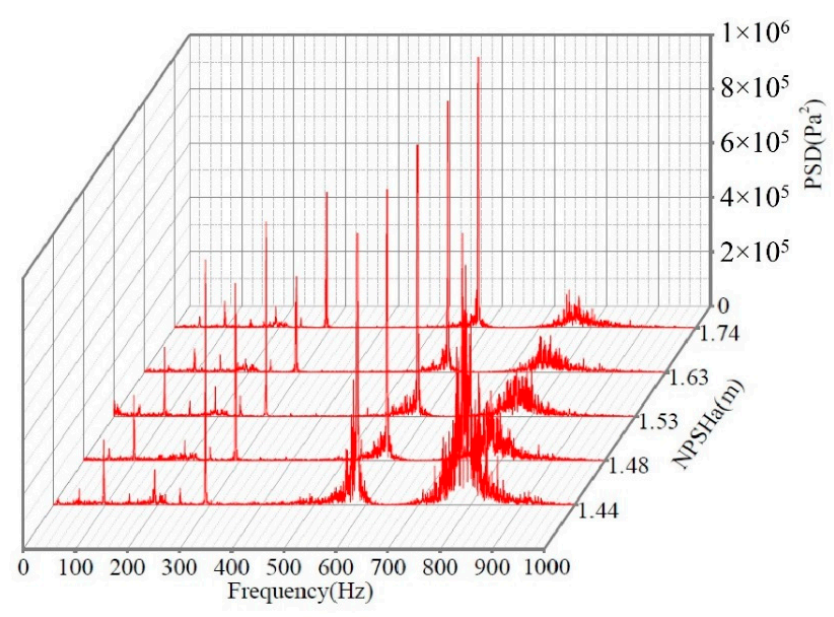

(a)

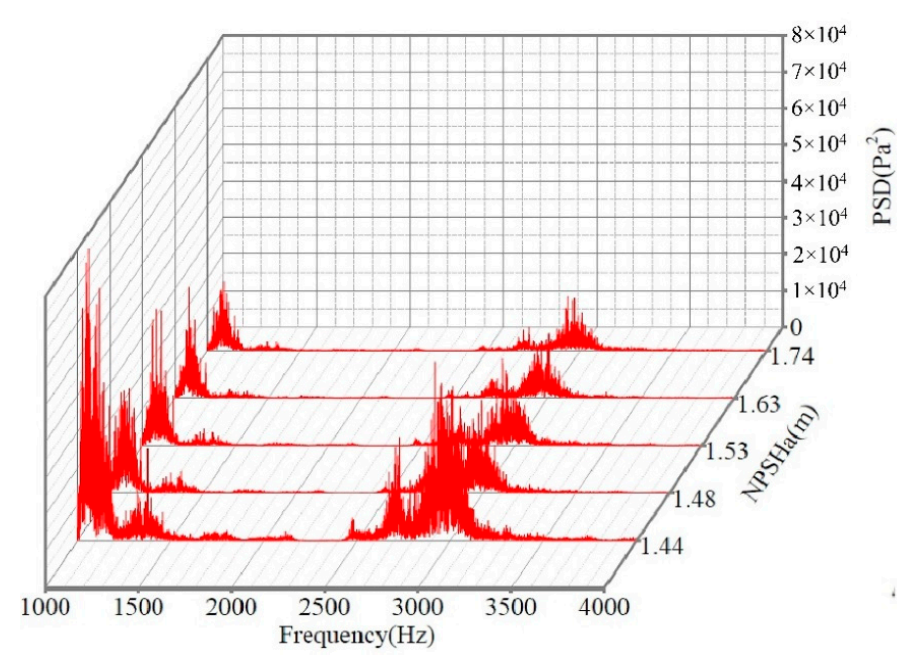

(b)

Figure 3. Frequency response characteristics of power spectral density (PSD) signal of sound pressure at outlet pipe with different available net positive suction head (NPSHa). (a) 0-1000 Hz; (b) $1000-4000 \mathrm{~Hz}$ [30].

In summary, the flow-induced noise of centrifugal pumps is associated with various flow phenomena. There have been great achievements in the analysis of the generation mechanism and 
frequency response characteristics of the noise induced by rotor-stator interaction and cavitation; meanwhile, the control strategy of the two kinds of noise has also been developed [19,32-35]. However, there are few studies concentrating on the analysis of the generation, distribution and control strategy of the noise induced by other factors with inconspicuous characteristics, which include turbulence, back flow, rotating stall and water hammer. Actually, during various operating conditions, the turbulence phenomenon exists in centrifugal pumps. The back flow, rotating stall and water hammer also appear in the process of condition regulation. Therefore, it is necessary to pay more attention to these kinds of noise in follow-up studies, to deepen the comprehensive understanding of the generation mechanism and distribution characteristics of flow-induced noise and to further promote the development of the noise control strategy.

(3) The noise propagation route

The centrifugal pump system consists of the inlet pipe, centrifugal pump and outlet pipe. The flow-induced noise will not only propagate to the inlet and outlet pipes, namely the internal flow noise, but will also propagate to the external environment, namely the external radiation noise [36].

\section{Study Methodologies}

Studies on the flow-induced noise generated by complex phenomena could be catalogued into three aspects, including the theoretical study of hydrodynamic noise, numerical simulation and experimental measurement.

\subsection{Theoretical Study of Hydrodynamic Noise}

Theoretical studies analyze the flow-induced noise through the governing equation level. The flow and sound fields have the same governing equation and the parameters of flow and sound fields could be obtained simultaneously by solving the compressible Navier-Stokes (N-S) equation directly in theory. However, it is difficult realize due to the huge difference in scale and magnitude between flow and sound fields [37]. Therefore, relevant sound theory is used. Table 2 summarizes the comparison of results between Lighthill acoustic analogy theory, vortex sound theory and acoustic/viscous splitting theory.

Table 2. Comparison between Lighthill acoustic analogy theory, Vortex sound theory and Acoustic/Viscous splitting theory.

\begin{tabular}{|c|c|c|c|}
\hline Sound Theory & $\begin{array}{c}\text { Lighthill Acoustic Analogy } \\
\text { Theory [38-40] }\end{array}$ & Vortex Sound Theory [41-46] & $\begin{array}{c}\text { Acoustic/Viscous Splitting } \\
\text { Theory }[47,48]\end{array}$ \\
\hline $\begin{array}{l}\text { Governing } \\
\text { equation }\end{array}$ & $\begin{array}{l}\text { Inhomogeneous sound wave } \\
\text { equation with sound source. } \\
\text { The left and right side items of } \\
\text { the sound wave equation are } \\
\text { wave operator and sound } \\
\text { source, respectively. }\end{array}$ & $\begin{array}{l}\text { Same as the form of the } \\
\text { governing equation of } \\
\text { "Lighthill acoustic } \\
\text { analogy theory." }\end{array}$ & $\begin{array}{l}\text { Compressible perturbation } \\
\text { equation of sound field is } \\
\text { obtained by subtracting the } \\
\text { incompressible N-S equation } \\
\text { of flow field from compressible } \\
\text { N-S equation based on } \\
\text { variable separation method. }\end{array}$ \\
\hline Sound source & $\begin{array}{l}\text { Monopole, dipole and } \\
\text { quadrupole sources. }\end{array}$ & $\begin{array}{l}\text { The stretching of the vortex } \\
\text { and the non-uniformity of } \\
\text { fluid kinetic energy. }\end{array}$ & / \\
\hline Advantages & $\begin{array}{l}\text { It is suitable for the frequency } \\
\text { response analysis and the } \\
\text { distribution characteristics } \\
\text { analysis of sound field in } \\
\text { frequency domain and the } \\
\text { improved calculation process } \\
\text { has been formed. }\end{array}$ & $\begin{array}{l}\text { The time-domain parameters } \\
\text { of sound field could be } \\
\text { obtained directly. It is suitable } \\
\text { for the interpretation of the } \\
\text { generation and distribution of } \\
\text { flow-induced noise. }\end{array}$ & $\begin{array}{l}\text { Same as the advantages of } \\
\text { "Vortex sound theory." }\end{array}$ \\
\hline Shortages & $\begin{array}{l}\text { Fluid viscosity is ignored. It } \\
\text { could not explain the } \\
\text { generation and distribution } \\
\text { mechanism of } \\
\text { flow-induced noise. }\end{array}$ & $\begin{array}{l}\text { Fluid viscosity is ignored. The } \\
\text { solution process is relatively } \\
\text { complicated and the improved } \\
\text { calculation process has not } \\
\text { been formed. }\end{array}$ & $\begin{array}{l}\text { The solution process is more } \\
\text { complicated than that of } \\
\text { "Vortex sound equation" and } \\
\text { the improved calculation } \\
\text { process has not been formed. }\end{array}$ \\
\hline
\end{tabular}




\subsection{Numerical Simulation Study}

Due to the obscurity of theoretical study, it is necessary to combine the theoretical conclusions with numerical simulation. Compared with the experimental measurement, the numerical simulation method has the advantages of a low cost and short cycle and so forth. With the development of the computer performance, both the calculation accuracy and speed have improved significantly. Computational Fluid Dynamics (CFD) is currently the most efficient method for analyzing the flow and flow-induced noise [49-52]. It is worh noting that the empirical model and assumption are used in the simulation process, so the experimental validation is essential.

The numerical simulation of flow-induced noise is mainly guided by Lighthill acoustic analogy theory and is combined with CFD software. The simulation process could be divided into two steps [53]. The first step is to obtain the unsteady flow characteristics [54-58] by adopting a suitable turbulence model [57-62]. The second step is to extract the unsteady flow fluctuations in walls which are used as a dipole source, and then to use the finite element method, infinite element method or boundary element method to solve the sound wave equation [63-65].

The generation of noise is accompanied by the vibration of pump structures, so the noise simulation method that only considers the dipole source has some limitations. With the deepening of study, scholars have adopted the acoustic-vibration-coupling method, which is realized by taking the modal response results of structures into consideration, to analyze the flow-induced noise under the joint action of structural vibration and dipole source [66-72].

\subsection{Experimental Measurement Study}

Compared with the theoretical analysis and numerical simulation method, the most direct method is experimental measurement, including indirect measurement and direct measurement.

The indirect measurement method is to measure and analyze the parameters that are related to flow-induced noise such as pressure [73-75], velocity [12,76-78] and vibration signal [79-83], then establish the relationship between these parameters and flow-induced noise. Different from the indirect measurement, the direct measurement is more convenient and it is realized by measuring the flow-induced noise directly. However, owing to the high-pressure and high-speed rotating characteristics of centrifugal pumps, the measurement of internal flow noise is to measure the flow noise at inlet and outlet pipes by using a flush-mounted hydrophone, while the external radiation noise is measured by a microphone at the monitoring points arranged evenly outside pumps. Besides, it is also difficult to distinguish the contributions of different noise sources, especially the flow-induced noise and mechanical vibration noise. Therefore, the experimental measurement is always combined with numerical simulation for relevant analysis.

It is common knowledge that the change of noise is accompanied by the change of pressure, flow rate and so forth. Yuan et al. [84] designed a hydraulic performance and flow-induced noise measurement system based on LabVIEW, which realized the synchronous measurement of the head, flow rate and flow-induced noise. The system is beneficial for the understanding of the pump operating condition and has been adopted by many scholars [79,80,85].

\section{The Study about the Distribution Characteristics of Flow-Induced Noise}

\subsection{Noise Source Identification and Comparison}

Actually, various flow phenomena exist in different flow passage components of centrifugal pump systems, which include impeller, volute, vane, leakage passage and so on [86-88]. The various flow phenomena are combined into a noise source for flow-induced noise calculation, which makes the noise source identification and comparison an important part of the distribution characteristics analysis of flow-induced noise. For centrifugal pumps with different structures, the unsteady flow fluctuations in different flow passage components have different contributions to overall noise. As the main flow passage components, the impeller and volute are widely considered. Guo et al. [89] proposed that the 
noise source could be identified qualitatively and quantitatively by calculating the standard deviation (STD) of the noise source. As shown in Figure 4, the maximum of STD in volute is located near the volute tongue and extends downstream slightly along the impeller rotation direction, which is much higher than that in other regions and is the main noise source region. He et al. [90] also compared sound pressure intensity generated by impeller and volute dipole sources based on Lighthill acoustic analogy theory and found that the minimum of sound pressure intensity induced by the volute dipole source is about $26 \mathrm{~dB}$ higher than the maximum of sound pressure intensity induced by the impeller dipole source and the maximum is located near the volute tongue, which also shows that the volute dipole source is the main noise source.

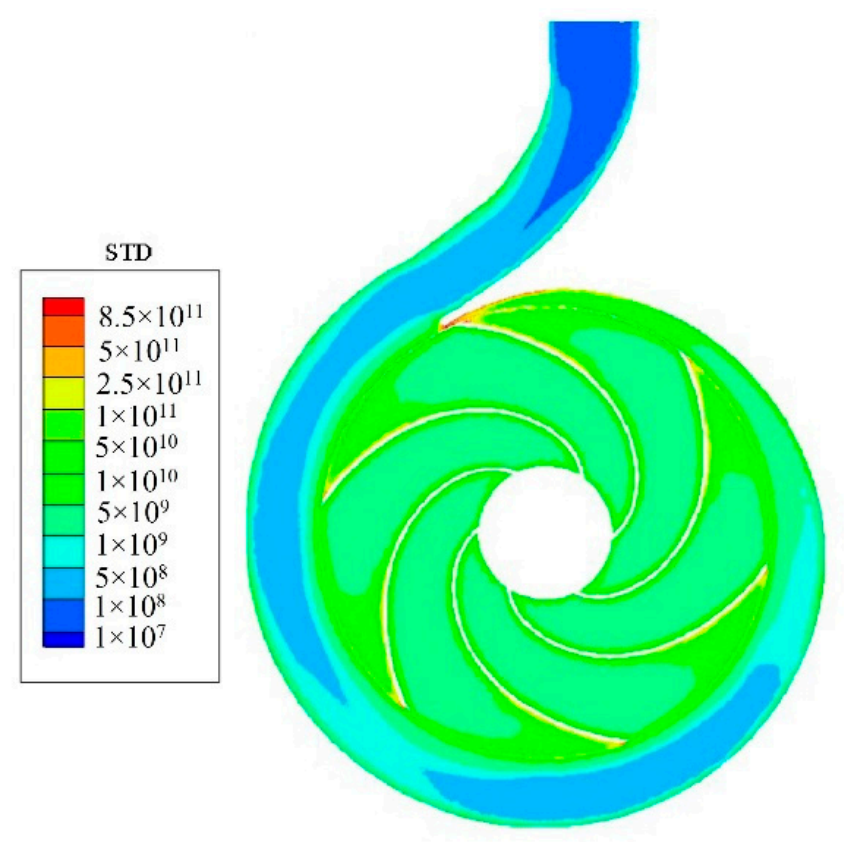

Figure 4. The STD distribution characteristics of noise source [89].

Besides the dipole source being obtained by unsteady flow fluctuations, the vibration of pump structures induced by flow could also induce noise, namely the flow-induced structure noise [72], which implies that the vibration is also a kind of noise source. To compare the vibration at different locations of the centrifugal pump system, Liu et al. [80] measured the vibration intensity at different locations of the pump system by using an acceleration sensor, as shown in Figure 5. It is observed that the vibration intensity at the pump body is the largest, followed by pump foot and the vibration intensity at inlet and outlet flanges is the lowest, which means that the vibration of the pump body contributes more to overall noise. The analysis above only discusses the overall vibration intensity at different locations, while the analysis of the relationship between vibration and noise is not involved. Based on coherence analysis, Zhou et al. [83] analyzed the distribution characteristics of the vibration signal and noise signal in the frequency domain, as shown in Figure 6. The coherence coefficient between vibration and noise is close to 1 at characteristic frequencies, which further reveals the relationship between vibration and noise. 


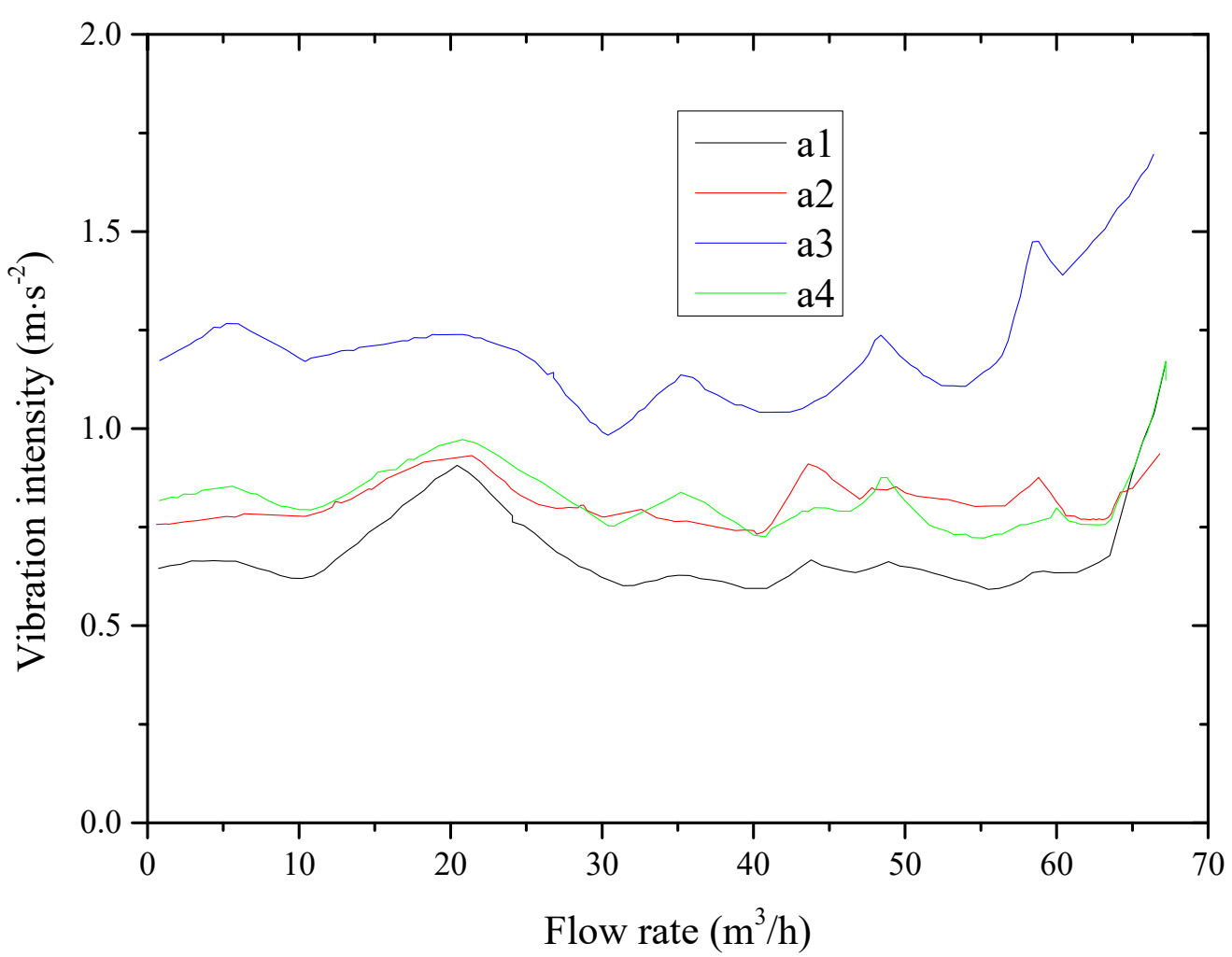

Figure 5. The vibration intensity at different locations of pump system. (a1) inlet flange; (a2) outlet flange; (a3) pump body; (a4) pump foot [80].

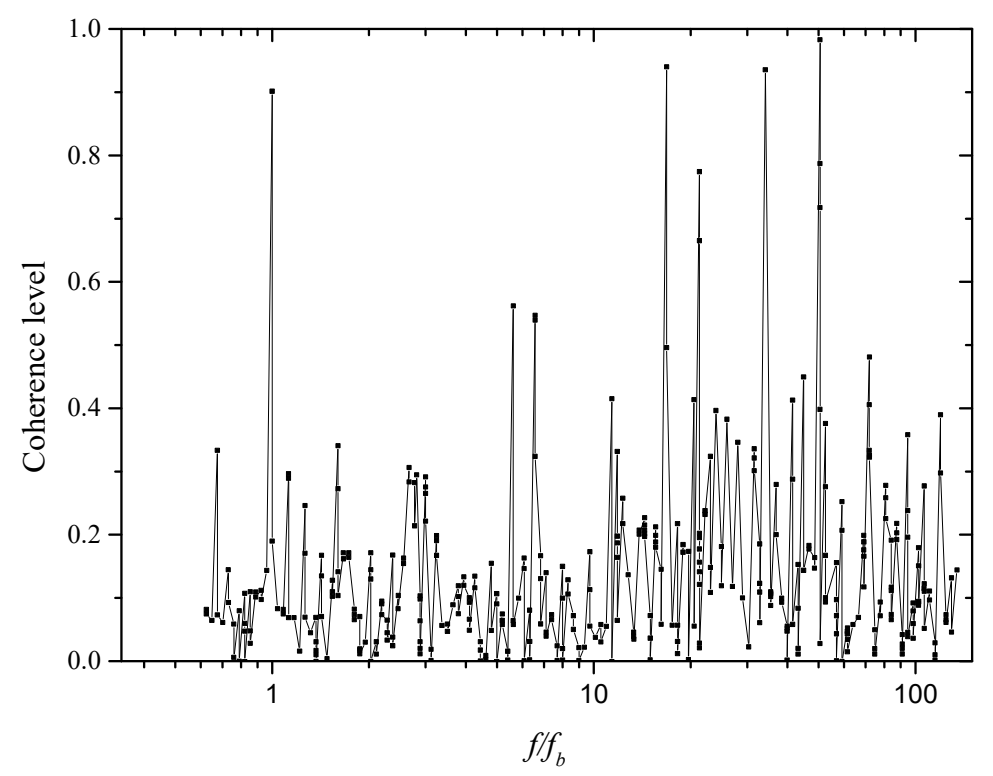

(a)

Figure 6. Cont. 


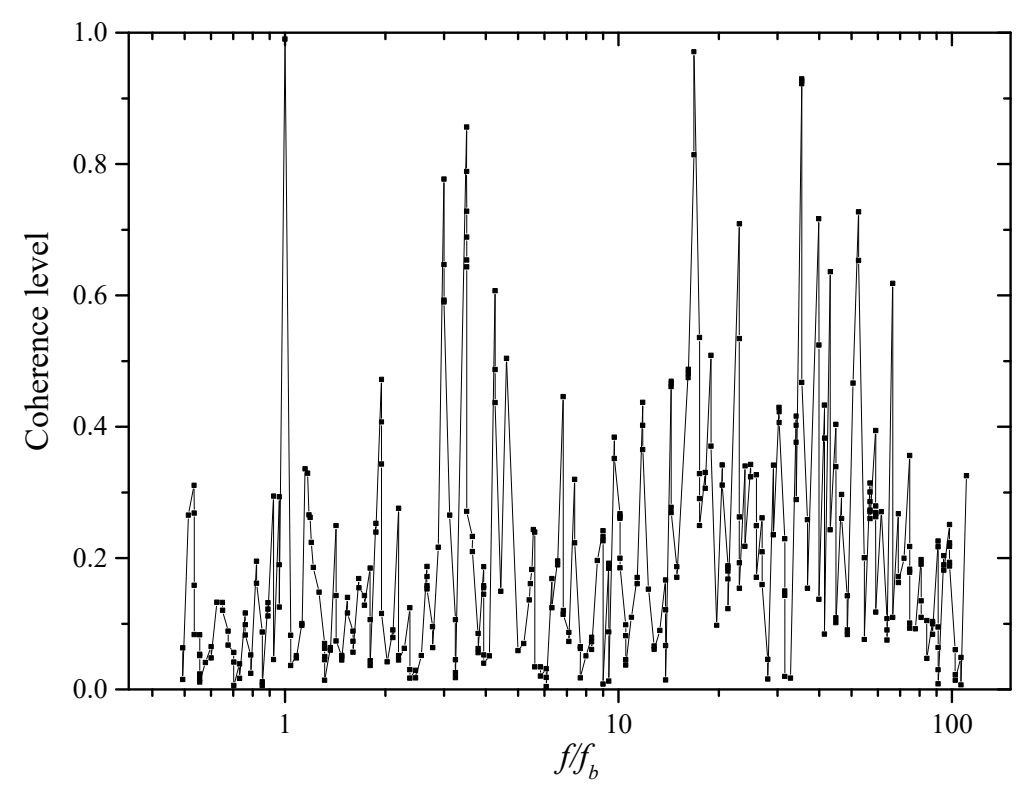

(b)

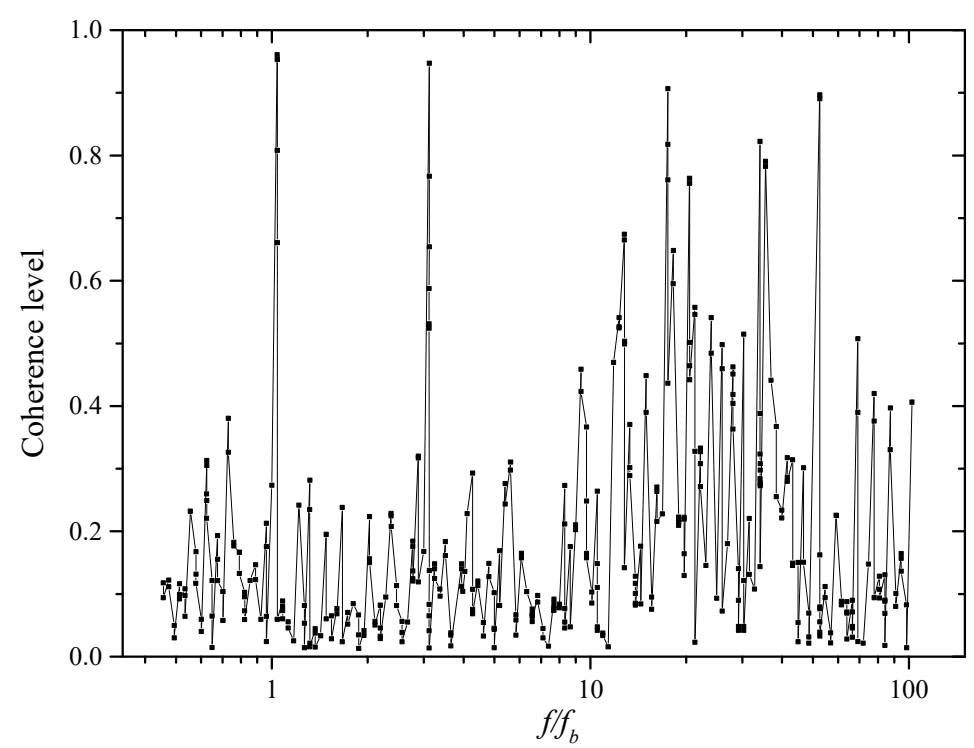

(c)

Figure 6. Coherence level of vibration and noise signals in frequency domain near the outlet pipe.

(a) $8660 \mathrm{rpm}$; (b) 10,825 rpm; (c) 12,000 rpm [83].

In addition, to further compare the effect of dipole source and vibration on flow-induced noise, Dong et al. [72,91] compared the internal flow noise and external radiation noise obtained by different noise sources, as shown in Figures 7 and 8. By comparing Figures 7 and 8, it is found that the noise source has different contributions to internal flow noise and external radiation noise. Specifically, the flow-induced noise obtained by a casing (volute, cover, inlet and outlet pipes) dipole source is the highest inside the pump, while the flow-induced structure noise obtained by the acoustic-vibration-coupling method is the highest outside the pump. The analysis reveals that the casing dipole source contributes most to internal flow noise, while the vibration excited by unsteady flow fluctuations makes the biggest contribution to external radiation noise. 


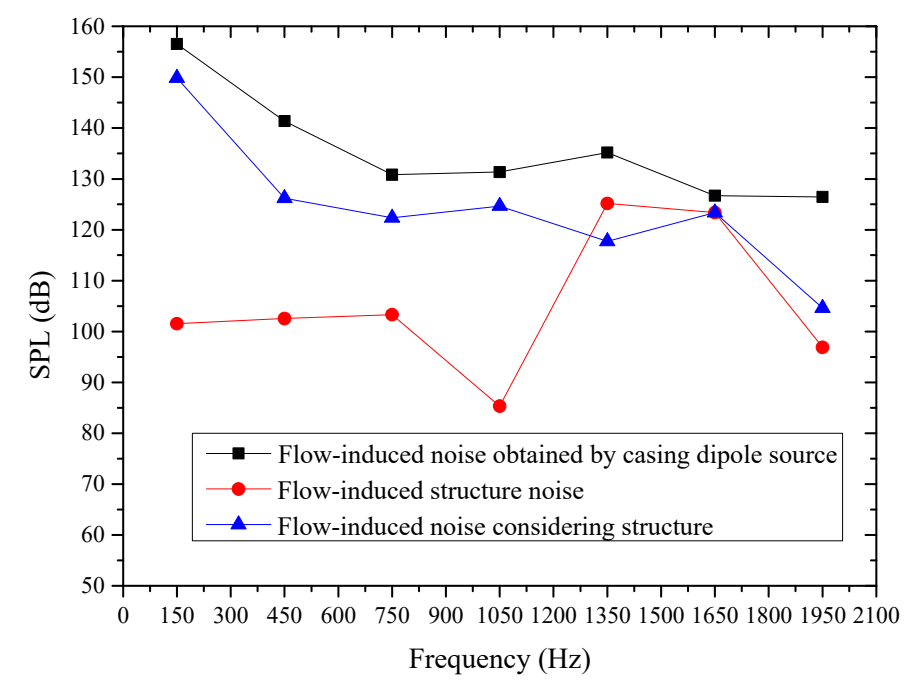

Figure 7. The comparison of internal flow noise obtained by different noise sources [91].

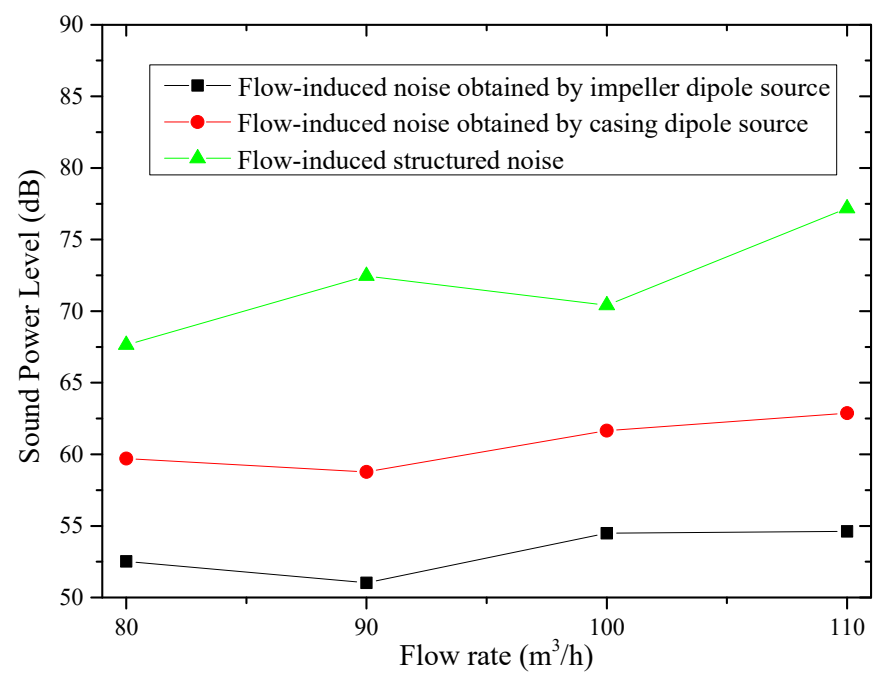

Figure 8. The comparison of external radiation noise obtained by different noise sources [72].

\subsection{Frequency Response Analysis of Flow-Induced Noise}

Under the influence of the noise source, specific frequency response characteristics of flow-induced noise are formed. Frequency response analysis is undertaken to figure out the noise distribution in the frequency domain and the noise amplitude at different frequencies, which could provide guidelines for noise elimination and reduction. Figures 2 and 3 show the frequency response results of two kinds of flow phenomena. Besides, the frequency response analysis is also used for the accuracy verification of the numerical simulation method. To verify the accuracy of the numerical simulation method, the most commonly used object is the internal flow noise at the outlet pipe. As shown in Figure 9, the SPL obtained by simulation and experiment reaches a peak at each characteristic frequencies and shows a trend of fluctuating downward with the increase of frequency, which not only reveals the frequency response results but also manifests the accuracy of the numerical simulation method. 


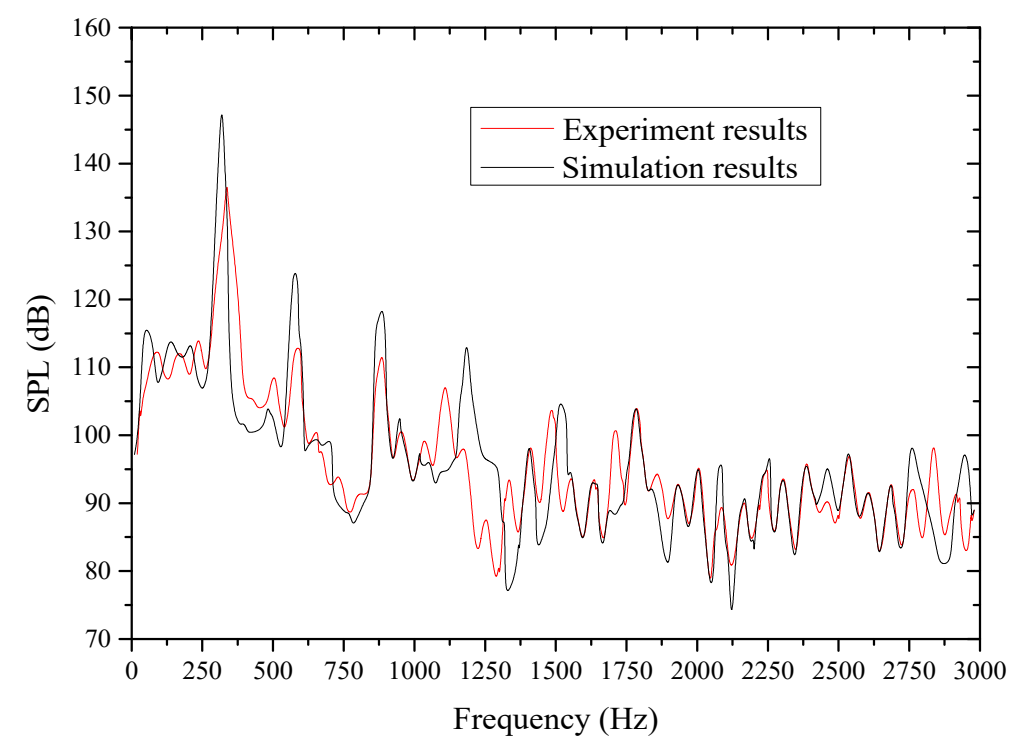

Figure 9. The frequency response results of internal flow noise [21].

Figure 10 shows the frequency response results of external radiation noise. With the frequency increasing from 31.5 to $1000 \mathrm{~Hz}$, the SPL follows a fluctuating ascending trend and reaches a peak at each order of $f_{s}$ (shaft-passing frequency) and $f_{b}$. The maximum value appears between 1000 and $2000 \mathrm{~Hz}$ [92,93]. When the frequency is higher than $2000 \mathrm{~Hz}$, the SPL decreases gradually. It is revealed that the frequency response characteristics of external radiation noise are different from those of internal flow noise, while the mechanism that causes the difference between internal flow noise and external radiation noise has not been revealed yet.

The vibration of pump structures has different contributions to internal flow noise and external radiation noise, which means that it could also affect the frequency response characteristics. Table 3 compares the impact of an acoustic-vibration-coupling effect on frequency response characteristics. As can be seen, the vibration of pump structures has the opposite effect on the noise at specific frequencies inside and outside pumps.

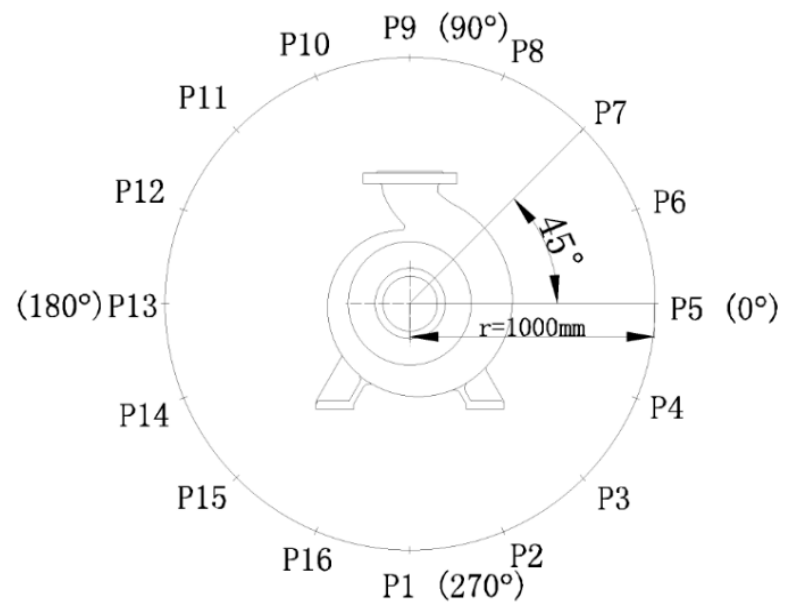

(a)

Figure 10. Cont. 


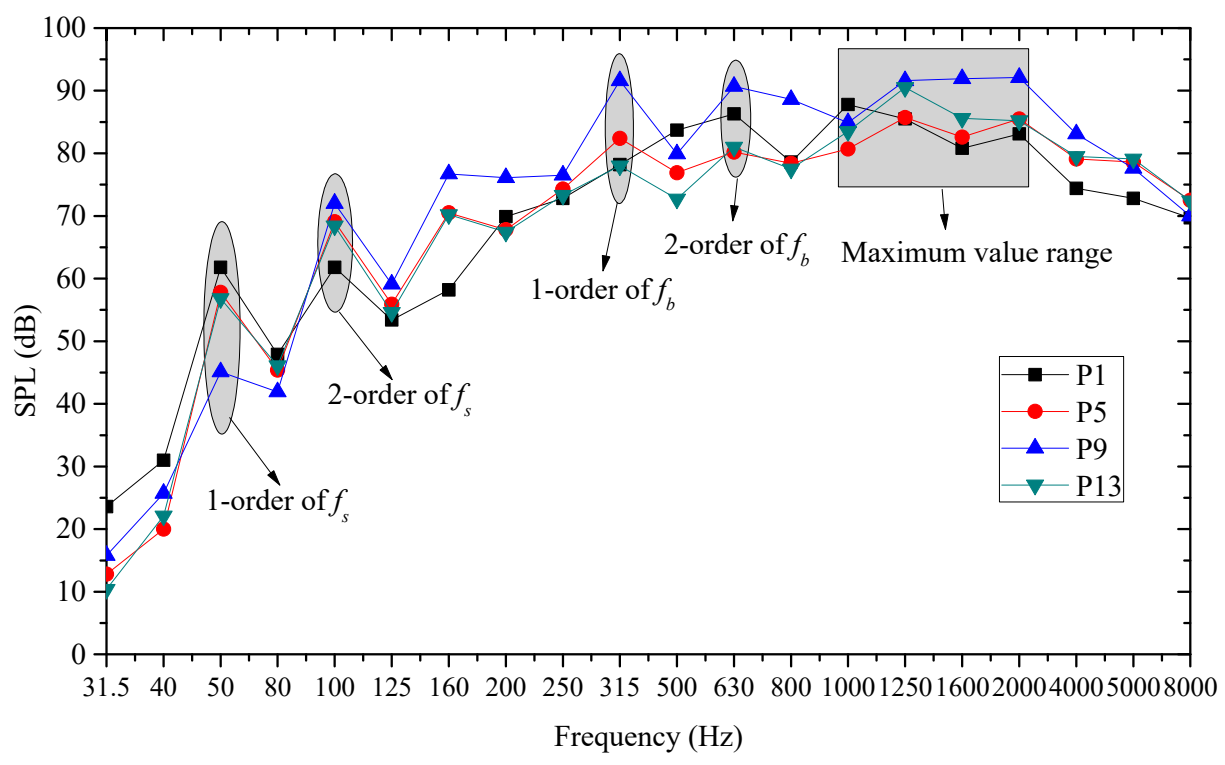

(b)

Figure 10. The frequency response results of external radiation noise. (a) Monitoring points arrangement; (b) Frequency response results of different monitoring points [93].

Table 3. The impact of acoustic-vibration-coupling effect on frequency response characteristics of flow-induced noise.

\begin{tabular}{cccc}
\hline Study Object & References & $\begin{array}{c}\text { Impact on Frequency } \\
\text { Response Characteristics }\end{array}$ & Key Findings \\
\hline $\begin{array}{c}\text { Internal } \\
\text { flow noise }\end{array}$ & {$[68,69]$} & $\begin{array}{c}\text { The 2-order of } f_{b} \text { is close to the } \\
\text { 1-order of natural frequency, the } \\
\text { SPL at 2-order of } f_{b} \text { decreases. }\end{array}$ & $\begin{array}{c}\text { The vibration of volute could } \\
\text { cause the sound energy } \\
\text { dissipation. Due to the reflection } \\
\text { and scatter effects, the volute } \\
\text { could prevent the internal noise } \\
\text { from propagating to outside. }\end{array}$ \\
\hline $\begin{array}{c}\text { External } \\
\text { radiation } \\
\text { noise }\end{array}$ & {$[72]$} & $\begin{array}{c}\text { The 2-order and 5-order of } f_{b} \text { are } \\
\text { close to the 1-order and 3-order of } \\
\text { natural frequencies, the SPL at } \\
\text { 2-order and 5-order of } f_{b} \text { is higher. }\end{array}$ & $\begin{array}{c}\text { The external radiation noise is the } \\
\text { result of joint action of the internal } \\
\text { pressure fluctuations and } \\
\text { structure vibration. }\end{array}$ \\
\hline
\end{tabular}

\subsection{Directivity Characteristics Analysis of Sound Field}

In the internal and external fields of centrifugal pumps, the noise at different locations changes with the changing direction and distance of monitoring locations relative to the noise source and thereby specific directivity characteristics are formed. Due to the particularity of centrifugal pump structures, the directivity distribution characteristics in the circumferential direction have received much attention [94-100]. Because of the measurement difficulty, the directivity characteristics of the internal sound field are analyzed based on numerical simulation, while those of external sound field could be analyzed by the combination of numerical simulation and experimental measurement.

Based on the results of frequency response analysis at different monitoring points, the directivity characteristics of the sound field could be obtained. Figures 11 and 12 present the directivity characteristics of the internal sound field when the flow rate is $15 \mathrm{~m}^{3} / \mathrm{h}[94,95]$. The dipole directivity characteristics are presented in Figures $11 \mathrm{~b}$ and 12 and the maximum of SPL at $f_{b}$ and TSPL appears near the tongue. Figure 13 illustrates the directivity characteristics of the external sound field induced by impeller and volute dipole sources. The TSPL induced by the impeller dipole source presents the dipole directivity characteristics, while the TSPL near the tongue is higher than that far away from 
the tongue when the volute dipole source is considered the noise source, which are similar to the directivity characteristics of the internal sound field. Besides, Guo et al. [98] conducted an experiment to verify the accuracy of directivity characteristics of the external sound field. As shown in Figure 14, the TSPL illustrates similar dipole symmetric distribution and asymmetric distribution characteristics. The results verify that the directivity characteristics are the result of joint action of impeller and volute. Based on previous studies, Guo et al. [101] also proposed that the directivity characteristics of a noise source due to the unsteady flow fluctuations lead to those of the internal sound field and further cause those of the external sound field.

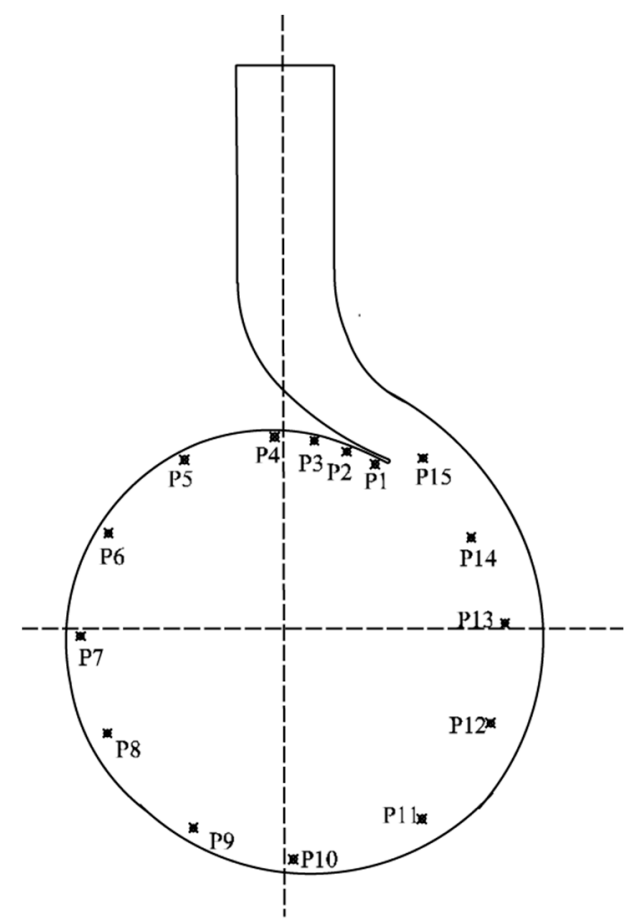

(a)

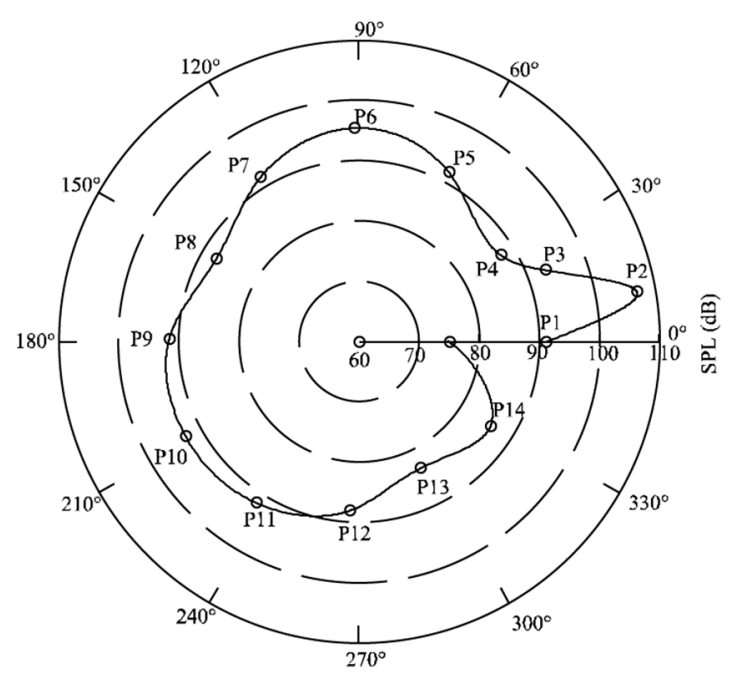

(b)

Figure 11. Sound pressure level (SPL) directivity characteristics at $f_{b}$ of internal sound field obtained by simulation when the flow rate is $15 \mathrm{~m}^{3} / \mathrm{h}$. (a) Arrangement of monitoring points; (b) SPL directivity characteristics at $f_{b}[94]$. 


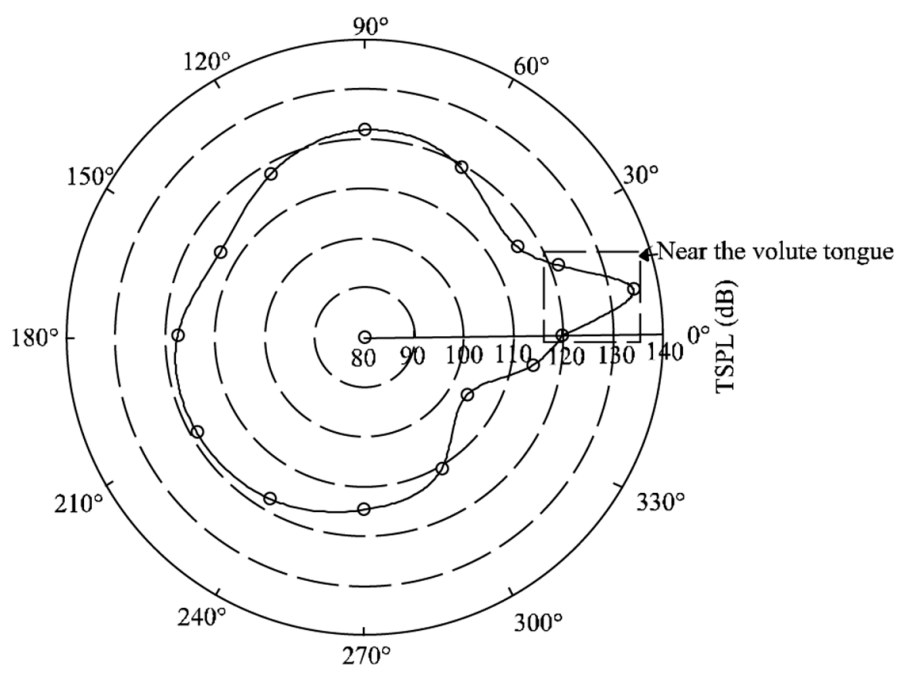

Figure 12. Total sound pressure level (TSPL) directivity characteristics of internal sound field obtained by simulation when the flow rate is $15 \mathrm{~m}^{3} / \mathrm{h}$ [95].

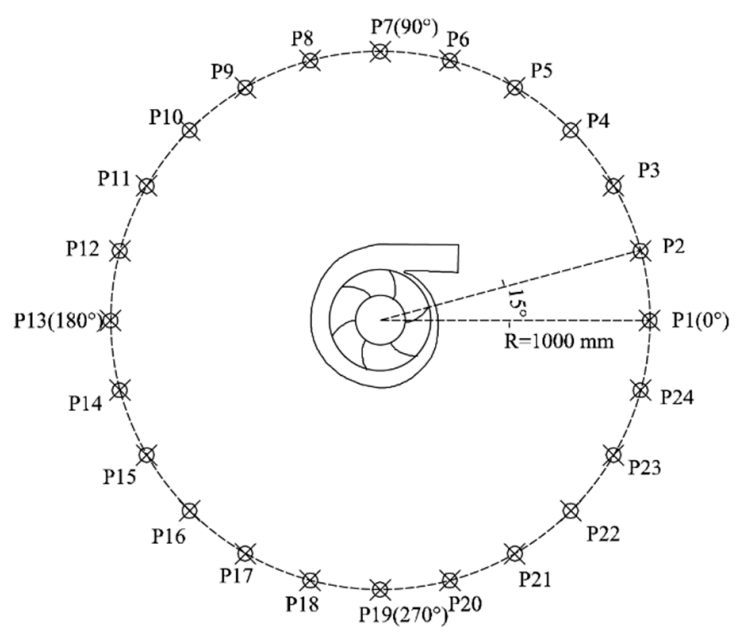

(a)

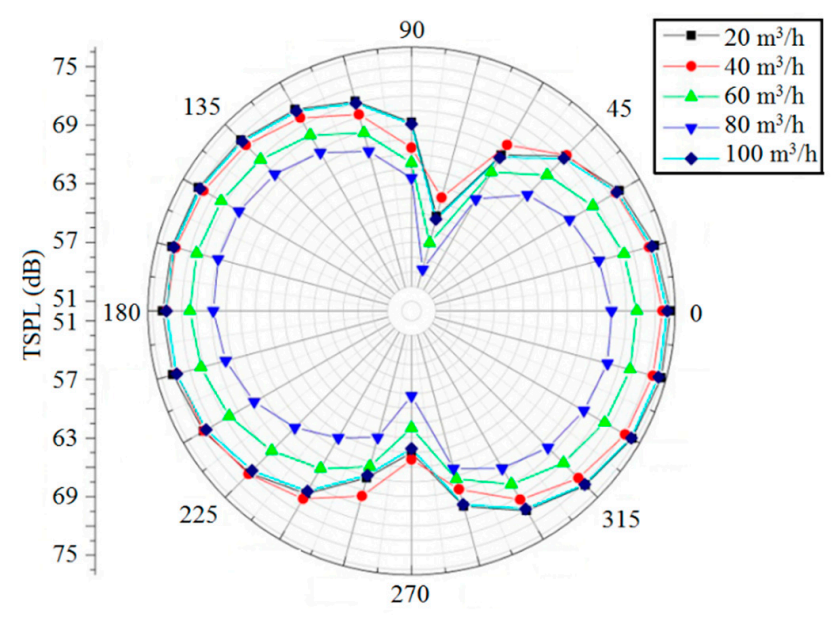

(b)

Figure 13. Cont. 


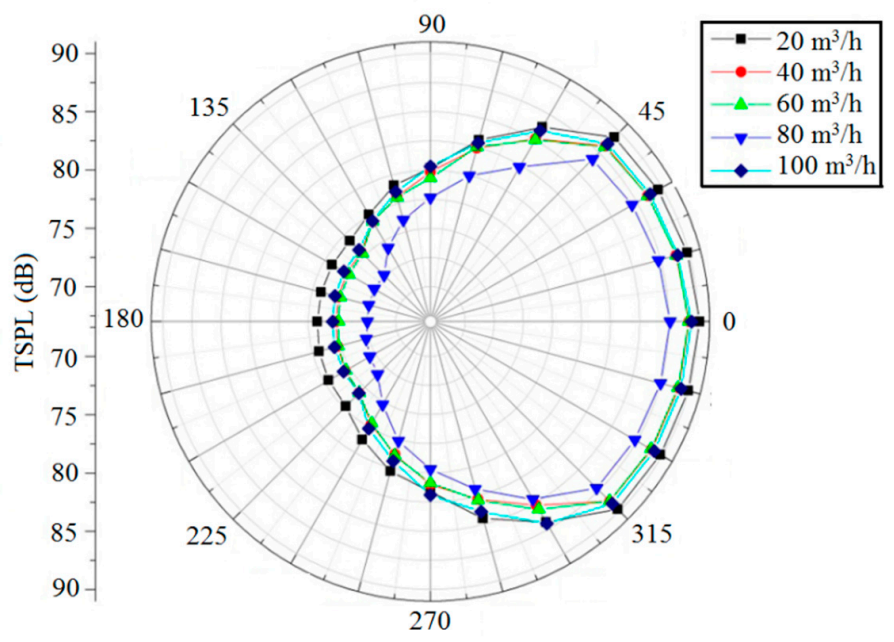

(c)

Figure 13. TSPL directivity characteristics of external sound field obtained by simulation. (a) Arrangement of monitoring points; (b) TSPL directivity characteristics induced by impeller dipole source; (c) TSPL directivity characteristics induced by volute dipole source [96].

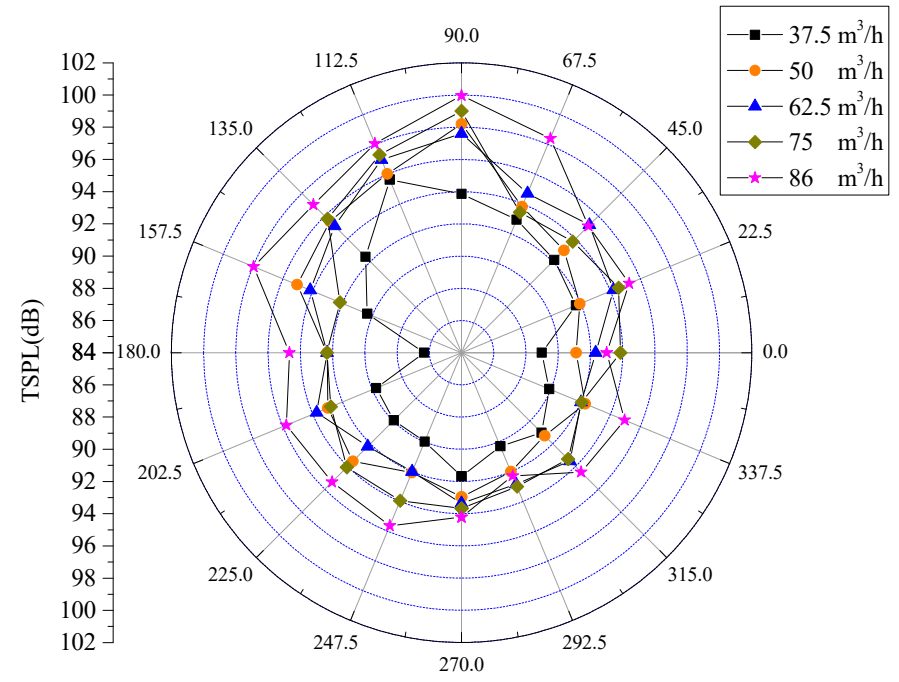

Figure 14. TSPL directivity characteristics of external field obtained by experiment [98].

With the development of the study, the noise directivity characteristics in axial and horizontal direction are also discussed [102-106], so that the spatial directivity characteristics are revealed comprehensively.

\subsection{Noise Changing Characteristics Analysis under Various Operating Conditions}

The centrifugal pumps always need to operate under various conditions to meet corresponding working demands and the flow-induced noise changes accordingly. The analysis of the noise changing characteristics is always included in the other studies mentioned above. Figures 15-17 depict the experimental results of internal flow noise changing curves at inlet and outlet pipes with different rotational speeds [107], flow rates [20] and medium temperatures [108,109], respectively. It is found that the noise at inlet and outlet pipes shows a similar changing trend and the noise at the outlet pipe is higher than that at the inlet pipe. With the growth of rotational speed, the noise at the inlet and outlet pipes increases gradually. Under different flow rates, the noise at inlet and outlet pipes reaches a minimum at a rated operating condition, that is, near the best efficiency condition and increases at 
off-design conditions. Besides, it is found from Figure 18 that the medium temperature could also affect the noise level and the noise at inlet and outlet pipes reaches a maximum at a certain temperature.

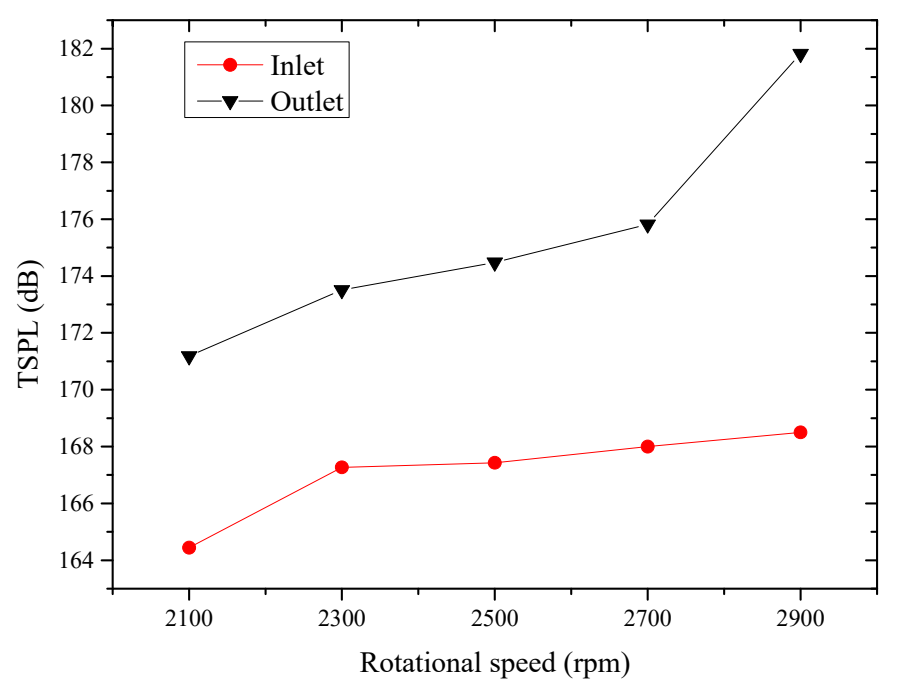

Figure 15. The changing curves of internal flow noise at inlet and outlet pipes with different rotational speeds [107].

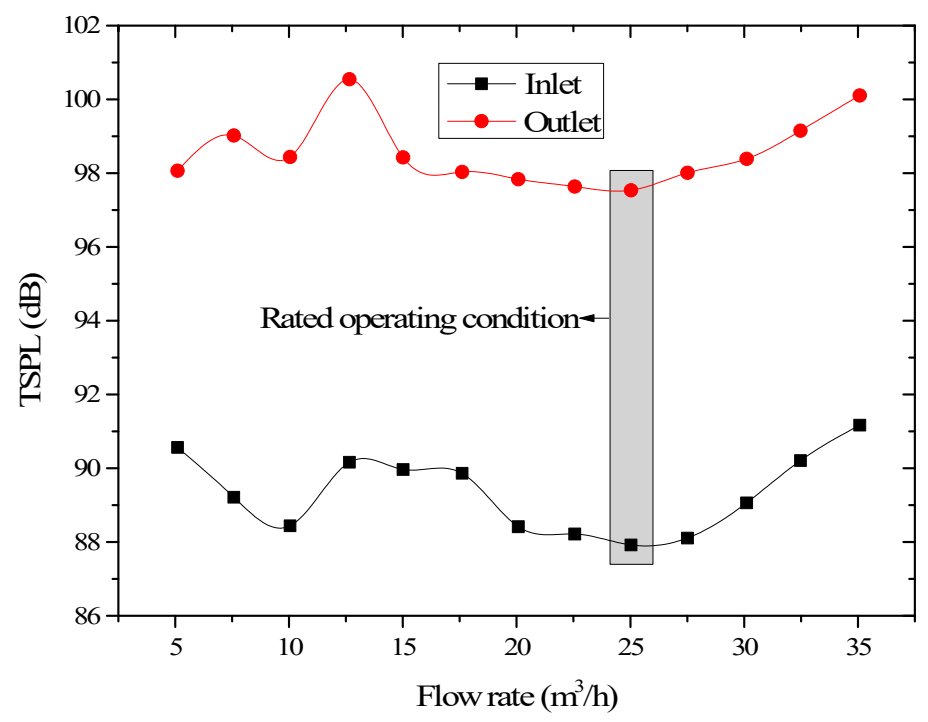

Figure 16. The changing curves of internal flow noise at inlet and outlet pipes with different flow rates [20].

The changing trend of external radiation noise and internal flow noise is similar under different rotational speeds, while that of different flow rates is different. Figure 18 depicts the experimental results of external radiation noise changing curves with different flow rates [99], where P1-P13 are the monitoring points shown in Figure 10a. It is observed that the external radiation noise follows an increasing trend with the growth of flow rate, which is different from the trend of internal flow noise by comparing Figures 16 and 18. However, the mechanism that leads to the difference of changing trend still needs to be explored further. 


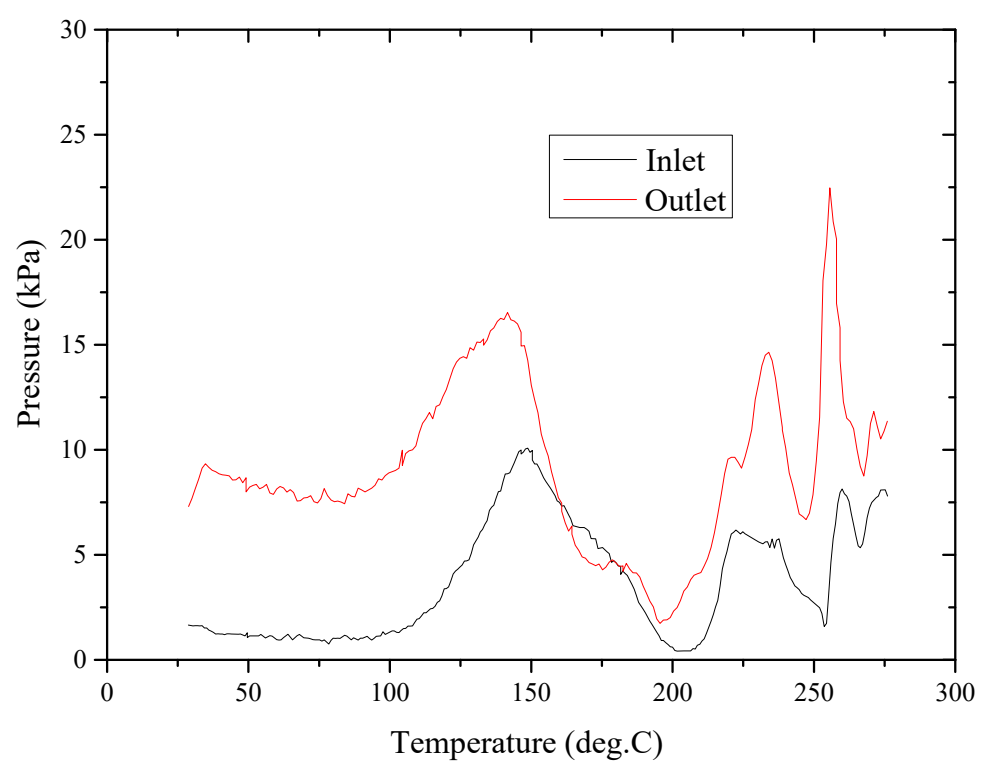

Figure 17. The changing curves of internal flow noise at inlet and outlet pipes with different medium temperatures [108].

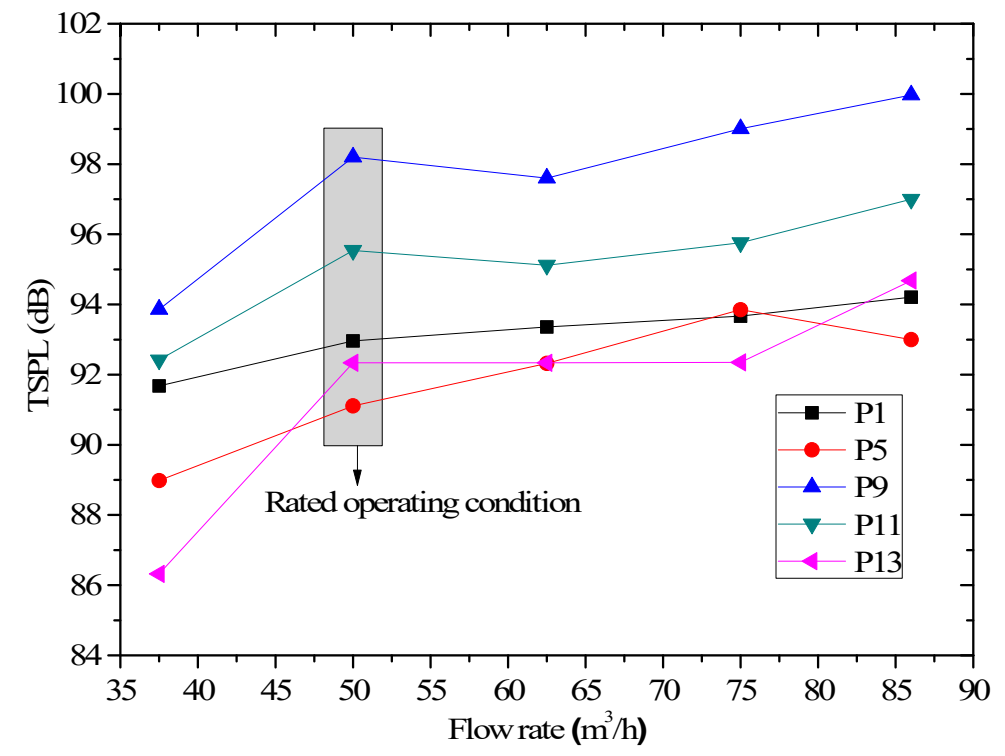

Figure 18. The changing curves of external radiation noise with different flow rates [98].

In summary, based on the above analysis in Sections 2-4, it could be concluded that remarkable results have been gained from analyzing the noise generation and distribution characteristics from using different study methodologies. On this foundation, the flow-induced noise propagation mechanism still needs to be further explored, to form a systematic analysis model of the noise generation, distribution and propagation mechanism. The analysis of the noise propagation mechanism could not only extend the noise evaluation criterion but also lay a foundation for flow-induced noise reduction from the view of the noise propagation route.

Besides, the generation of noise and vibration is associated with the unsteady flow characteristics. It is indispensable to take the flow field effect into account on the basis of the acoustic-vibration-coupling method, to further improve the numerical simulation method.

Additionally, in the process of experimental measurement, the measurement object and mode are relatively monotonous currently and only the noise at representative monitoring positions is measured. Considering the limitation of the current experimental measurement, it is necessary to develop new 
measurement technology to realize the real-time measurement of the whole sound field of centrifugal pumps, namely the visualization of the sound field.

\section{Noise Optimization Design of Centrifugal Pumps}

The purpose of the study on the generation and distribution characteristics of flow-induced noise is to lay a foundation for noise optimization design. As the final goal, the noise optimization design could be realized by reducing the sound power conversion rate, cutting off the noise propagation path and controlling the noise source $[110,111]$. The most effective optimization method is the noise source control which includes active control and passive control. The former is to reduce or eliminate the vibration and noise by attaching excitation source with the opposite phase [33]. The latter is to reduce the rotor-stator interaction intensity of centrifugal pumps by changing the structural material, shape and size and it is currently the most commonly used method for the noise optimization design of centrifugal pumps. The analysis results of passive control are summarized in Table 4.

Table 4. Analysis results of passive control.

\begin{tabular}{|c|c|c|}
\hline Pump Structures & References & Key Findings \\
\hline $\begin{array}{l}\text { Impeller outlet } \\
\text { width }\end{array}$ & {$[112,113]$} & $\begin{array}{l}\text { - The decrease of impeller outlet width weakens the pressure } \\
\text { fluctuations intensity and leads to the decrease of vibration } \\
\text { and noise. }\end{array}$ \\
\hline Impeller diameter & {$[32,85,114,115]$} & $\begin{array}{l}\text { The decrease of impeller diameter weakens the rotor-stator } \\
\text { interaction intensity and realizes the noise reduction, while it has } \\
\text { little impact on the directivity characteristics. } \\
\text { Critical value for the decrease of impeller diameter exists. The } \\
\text { noise reduction effect weakens when the decrease value exceeds } \\
\text { the critical value. }\end{array}$ \\
\hline Blade outlet angle & {$[102,116,117]$} & $\begin{array}{l}\text { The decrease of blade outlet angle weakens the fluctuations } \\
\text { intensity of noise source, which results in the noise reduction, } \\
\text { while it has little impact on the directivity characteristics. }\end{array}$ \\
\hline Blade type & {$[74,79,118-121]$} & 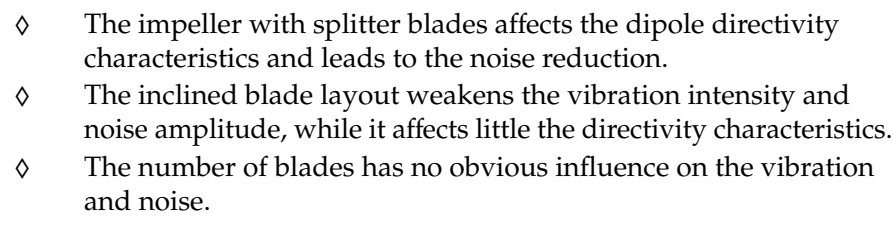 \\
\hline Vane wrap angle & {$[81,122]$} & $\begin{array}{l}\text { - The change of vane wrap angle has no obvious effect on the } \\
\text { vibration intensity and noise. }\end{array}$ \\
\hline $\begin{array}{l}\text { Blade inlet } \\
\text { incidence angle }\end{array}$ & [82] & $\begin{array}{l}\text { The change of blade inlet incidence angle has no obvious impact } \\
\text { on the vibration and noise. }\end{array}$ \\
\hline Structure material & [123] & $\begin{array}{l}\text { - The noise with 316L (one kind of anti-corrosion stainless steel) } \\
\text { used as port valve is the largest, followed by the noise with } \\
\text { NYLON (Aliphatic polyamides) used as port valve, the third one } \\
\text { is the noise with PEEK (Polyetheretherketone) used as port valve } \\
\text { and the noise with PTFE (Polytetrafluoroethylene) used as port } \\
\text { valve is the lowest. }\end{array}$ \\
\hline Inlet shape & [124] & $\begin{array}{l}\text { The straight inlet shape improves the unsteady fluctuation } \\
\text { characteristics inside the pump compared with the pre-rotating } \\
\text { inlet shape and leads to the reduction of pressure } \\
\text { fluctuations intensity. }\end{array}$ \\
\hline Volute shape & [125] & $\begin{array}{l}\text { The volute with rectangular cross section has a better noise } \\
\text { behavior than that with horseshoe-shaped cross section. } \\
\text { The noise obtained by volute with round edge cut-water is lower } \\
\text { than that obtained by volute with sharp edge cut-water. }\end{array}$ \\
\hline
\end{tabular}

Footer: "•"and " $\diamond$ " are used to distinguish the passive control results of different pump structures. 
It is noticeable that the flow-induced noise of centrifugal pumps is affected by various pump structures. On the basis of low flow-induced noise and high hydraulic performance, it is more ideal to explore the effect of various structure combinations on flow-induced noise and hydraulic performance. Then, the optimization algorithm is designed to analyze the influence of various factors on noise and hydraulic performance, as well as the corresponding influence proportion, so that the optimal geometric parameters could be obtained [126-130]. Predictably the optimization method effectively promotes the optimization development. However, the design of a variety of structures is tedious, expensive and time-consuming, so it is essential to establish a fast numerical simulation model for optimization design.

\section{Outlook for Future Study}

Benefiting from the development of computer technology, modern measurement techniques and related sound theory, great achievements have been realized regarding the analysis of the flow-induced noise of centrifugal pumps. By summarizing the study status, there are still some important areas for flow-induced noise of centrifugal pumps needing to be focused in the future.

From in-depth study on the generation mechanism of flow-induced noise, the contributions of different flow phenomena to overall flow-induced noise are not clear. Besides, there is no sufficient study on the generation mechanism and control strategy of noise induced by complex turbulence, back flow, rotating stall and water hammer. With the development of centrifugal pumps in the direction of large flow, high power and high load, as well as the demand for the change of operating conditions, the impact of these kinds of noise cannot be ignored. Therefore, an in-depth study on the generation mechanism of flow-induced noise is essential.

The improvement of the flow-vibration-acoustic-coupling method. The pressure fluctuations could induce noise and also induce the vibration of pump structures. The vibration could not only affect the flow field but also induce noise. Meanwhile, the generated-noise could affect structure vibration. Therefore, it is essential to further improve the noise simulation method by combining the flow field governing equation, the elastic structure dynamic equation and the sound field governing equation and establishing the coupling equation.

(1) Analysis model establishment of the generation, distribution and propagation mechanism for flow-induced noise. The analysis of the propagation mechanism of flow-induced noise, which has been proved that it is affected by the synergy of flow and sound fields in the process of fluid flow [131], is not involved in current study of the flow-induced noise of centrifugal pumps. It is beneficial for the prevention and control of flow-induced noise to establish the analysis model of the generation, distribution and propagation mechanism for flow-induced noise. The analysis model could be used for systematically analyzing the generation mechanism, the proportions of noise sources with different properties, the spatial-temporal distribution characteristics and the propagation characteristics of flow-induced noise.

(2) Development of high precision and fast numerical simulation method. There are three-dimensional steady and transient iterative calculation processes in the numerical simulation of flow-induced noise, which are tedious and time-consuming. To obtain high precision results, a large amount of grid system is required. Predictably, the development of high precision and fast simulation method could promote the study of flow-induced noise.

(3) Noise visualization experiment. To acquire the spatial distribution and dynamic changing characteristics of the flow-induced noise of centrifugal pumps more accurately, the real-time measurement of the whole sound field of centrifugal pumps should be conducted by developing the noise visualization technology. 


\section{Conclusions}

This paper reviews more than 130 articles to summarize the current study status on the flow-induced noise of centrifugal pumps. The review contents include the analysis of noise generation mechanisms and propagation routes, the study methodologies comparison, the distribution characteristics analysis of flow-induced noise and the analysis of noise optimization design. Then the outlook for future study is presented based on the literature review. The main conclusions are shown as follows:

(1) The flow-induced noise of centrifugal pumps is related to various complex flow phenomena. During the normal operating condition, the noise induced by rotor-stator interaction is the main component of overall noise. The rotor-stator interaction could cause the frequency response characteristics that are dominated by characteristic frequencies in a low frequency range. The cavitation could inhibit the rotor-stator interaction to some extent. With the development of cavitation, the frequency response characteristics of flow-induced noise that are dominated by characteristic frequencies weaken and the noise level in a high frequency range increases gradually. In addition, when the flow-induced noise generates inside centrifugal pumps, the noise could not only propagate to the inlet and outlet pipes but also propagate to the external environment, namely the internal flow noise and external radiation noise, respectively.

(2) Theoretical study, numerical simulation and experimental measurement are the main methodologies to analyze the flow-induced noise of centrifugal pumps. Theoretical study analyzes the subject through the governing equation level. Because of the obscurity of the theoretical study, the theoretical conclusions are always combined with numerical simulation. Numerical simulation is currently the most popular and versatile method to analyze the flow-induced noise by combining the Lighthill acoustic analogy theory with CFD and taking the acoustic-vibration-coupling effect into consideration, but the numerical simulation results need to be verified by experiment. For experimental measurement, the flow-induced noise could be directly measured but the measurement object and mode are relatively monotonous and the measurement results are affected by mechanical vibration.

(3) The analysis of the distribution characteristics of flow-induced noise mainly includes the noise source identification and comparison, the frequency response analysis, the directivity characteristics of sound field and the noise changing characteristics under various operating conditions. The main noise source region is located near the volute tongue and the volute dipole source has more contribution to internal flow noise compared with the impeller dipole source. Besides the dipole source, the vibration of pump structures induced by unsteady flow fluctuations is also a kind of noise source and it makes the biggest contribution to external radiation noise. Under the influence of a noise source, specific frequency response characteristics of flow-induced noise are formed and the internal flow noise shows a trend of fluctuating downward with the increase of frequency, while the maximum of external radiation noise appears between 1000 and $2000 \mathrm{~Hz}$. Based on the frequency response analysis results, directivity characteristics could be obtained. The internal flow noise and external radiation noise show the similar dipole directivity characteristics and the noise level near the tongue is higher than that far away from the tongue. The internal flow noise and external radiation noise increase with the growth of rotational speed. With the growth of flow rate, the internal flow noise reaches a minimum at rated operating conditions generally and increases at off-design conditions, while the external radiation noise increases gradually. Besides the effects of rotational speed and flow rate on noise, the medium temperature could also affect the noise level.

(4) As the final goal of the flow-induced noise study of centrifugal pumps, the noise optimization design is mainly realized by changing the pump structures to reduce the rotor-stator interaction intensity. However, different structures have different effects on the flow-induced noise. Therefore, it is required to consider the impacts of various structure variables and to combine the evaluation 
criteria of noise with that of hydraulic performance, then carry out multi-objective comprehensive optimization design.

(5) Based on the current study status, the in-depth study of the generation mechanism of flow-induced noise, the improvement of the fluid-vibration-acoustic-coupling method, the analysis model establishment of the generation, distribution and propagation mechanism for flow-induced noise and the development of high precision and fast numerical simulation method, as well as the development of noise visualization experiment need to be focused in future.

Author Contributions: M.G. proposed the idea for the article; C.G. performed the literature research and data analysis; C.G. wrote the manuscript; M.G. and S.H. revised the manuscript. All authors have read and agreed to the published version of the manuscript.

Funding: This research was funded by Key Research and Development Project of Shandong Province, grant number 2019GSF109084. And the APC was funded by Key Research and Development Project of Shandong Province.

Conflicts of Interest: The authors declare no conflict of interest.

\section{Nomenclature}

$\begin{array}{ll}\text { CFD } & \text { Computational Fluid Dynamics } \\ f_{b} & \text { Blade-passing frequency }(\mathrm{Hz}) \\ f_{s} & \text { Shaft-passing frequency }(\mathrm{Hz}) \\ n & \text { Number of frequencies }(-) \\ \text { NPSHa } & \text { Available net positive suction head }(\mathrm{m}) \\ \text { NYLON } & \text { Aliphatic polyamides }(-) \\ p^{\prime} & \text { Instantaneous sound pressure }(\mathrm{Pa}) \\ P_{e} & \text { Effective sound pressure }(\mathrm{Pa}) \\ P_{r e f} & \text { Reference sound pressure }(\mathrm{Pa}) \\ \text { PEEK } & \text { Polyetheretherketone }(-) \\ \text { PSD } & \text { Power spectral density }\left(\mathrm{Pa}{ }^{2}\right) \\ \text { PTFE } & \text { Polytetrafluoroethylene (-) } \\ \text { SPL } & \text { Sound Pressure Level (dB) } \\ \text { STD } & \text { Standard deviation (-) } \\ \text { T } & \text { Several rotational periods (s) } \\ \text { TSPL } & \text { Total Sound Pressure Level (dB) } \\ \text { 316L } & \text { One kind of anti-corrosion stainless steel (-) }\end{array}$

\section{References}

1. China Environmental Noise Prevention and Control Annual Report. Available online: http://www.mee.gov. cn/hjzl/sthjzk/hjzywr/ (accessed on 26 December 2019). (In Chinese)

2. Short, A.E.; Short, K.T.; Holdgate, A.; Ahern, N.; Morris, J. Noise levels in an Australian emergency department. Australas. Emerg. Nurs. J. 2011, 14, 26-31. [CrossRef]

3. Environmental Noise Guidelines for the European Region. Available online: http://www.euro.who.int/en/ health-topics/environment-and-health/noise/publications/2018/environmental-noise-guidelines-for-theeuropean-region-2018 (accessed on 10 October 2018).

4. Jurevicius, D.; Evans, T.; Stead, M. A New Approach to Implementing Facade Treatments in Context of the South Australian Road Traffic Noise Guidelines. Acoust. Aust. 2016, 44, 263-271. [CrossRef]

5. Gerges, S.N. Noise control policy in Brazil and South America. J. Acoust. Soc. Am. 2012, 131, 3328. [CrossRef]

6. Reuter, E.L. Applications of automatic equipment identification to studies of rail noise and vibration in North America. J. Acoust. Soc. Am. 2016, 140, 3094. [CrossRef]

7. Ma, K.; Wong, H.; Mac, C. Dental environmental noise evaluation and health risk model construction to dental professionals. Int. J. Environ. Res. Public Health 2017, 14, 1084. [CrossRef]

8. Gorica, M.; Branko, Z.; Lack, L. A review of the potential impacts of wind farm noise on sleep. Acoust. Aust. 2018, 46, 87-97.

9. Kamp, I.V.; Berg, F.V.D. Health Effects Related to Wind Turbine Sound, Including Low-Frequency Sound and Infrasound. Acoust. Aust. 2018, 46, 31-57. [CrossRef] 
10. Goelzer, B.; Hansen, C.H.; Sehrndt, G.A. Occupational Exposure to Noise Evaluation, Prevention and Control; World Health Organization: Geneva, Switzerland, 2001; pp. 80-81.

11. Jiang, A.; Zhang, Z.; Zhang, Y.; Hua, H. Review and outlook of studying on noise of centrifugal pumps. J. Vib. Shock 2011, 30, 77-84. (In Chinese)

12. Chu, S.; Dong, R.; Katz, J. Relationship between unsteady flow, pressure fluctuation, and noise in a centrifugal pump-Part A: Use of PDV data to compute the pressure field. J. Fluid Eng. 1995, 117, 24-29. [CrossRef]

13. Chu, S.; Dong, R.; Katz, J. Relationship between unsteady flow, pressure fluctuation, and noise in a centrifugal pump_Part B: Effects of blade-tongue interactions. J. Fluid Eng. 1995, 117, 30-35. [CrossRef]

14. José, G.; Joaquín, F.; Eduardo, B.; Carlos, S. Numerical simulation of the dynamic effects due to impeller-volute interaction in a centrifugal pump. J. Fluid. Eng. 2002, 124, 348-355.

15. Brennen, C.E. Cavitation and Bubble Dynamics; Cambridge University Press: New York, NY, USA, 2014; pp. 59-83.

16. Li, Y.; Feng, G.; Li, X.; Si, Q.; Zhu, Z. An experimental study on the cavitation vibration characteristics of a centrifugal pump at normal flow rate. J. Mech. Sci. Technol. 2018, 32, 4711-4720. [CrossRef]

17. Georgios, M.; Nilla, K.D.; George, A.; Ioannis, A.; Dimitrios, P. Experimental analysis of cavitation in a centrifugal pump using acoustic emission, vibration measurements and flow visualization. Eup. J. Mech. B-Fluid. 2019, 75, 300-311.

18. Choi, J.S.; Mclaughlin, D.K.; Thompson, D.E. Experiments on the unsteady flow field and noise generation in a centrifugal pump impeller. J. Sound Vib. 2003, 263, 493-514. [CrossRef]

19. Heng, Y. Numerical and Experimental Study on Flow-Induced Noise in Centrifugal Pumps. Master's Thesis, Jiangsu University, Zhenjiang, China, June 2014. (In Chinese)

20. Si, Q.; Yuan, S.; Yuan, J.; Liang, Y. Investigation on flow-induced noise impacted by backflow in low specific speed centrifugal pumps. Adv. Mech. Eng. 2013. [CrossRef]

21. Yang, J.; Yuan, S.; Pei, J.; Zhang, J. Overview of rotating stall in centrifugal pumps with vaned diffuser. J. Drain. Irrig. Mach. Eng. 2015, 33, 369-373. (In Chinese)

22. Guo, X. Research on Rotating Stall Characteristics in Centrifugal Pumps. Master's Thesis, China Agricultural University, Beijing, China, June 2015. (In Chinese)

23. Afshar, M.H.; Rohani, M. Water hammer simulation by implicit method of characteristic. Int. J. Pres. Ves. Pip. 2008, 85, 851-895. [CrossRef]

24. Ismaier, A.; Schlücker, E. Fluid dynamic interaction between water hammer and centrifugal pumps. Nucl. Eng. Des. 2009, 239, 3151-3154. [CrossRef]

25. Du, G.; Zhu, Z.; Gong, X. Fundamentals of Acoustics, 3rd ed.; Nanjing University Press: Nanjing, China, 2012; pp. 124-128. (In Chinese)

26. Guo, R.; Li, R.; Zhang, R. Reconstruction and Prediction of Flow Field Fluctuation Intensity and Flow-Induced Noise in Impeller Domain of Jet Centrifugal Pump Using Gappy POD Method. Energies 2019, $12,111$. [CrossRef]

27. Rui, X.; Zhao, Y. Numerical simulation and experimental research of flow-induced noise for centrifugal pumps. J. Vibroeng. 2016, 18, 622-636.

28. McNulty, P.J.; Pearsall, I.S. Cavitation Inception in Pumps. J. Fluid Eng. 1982, 104, 99-104. [CrossRef]

29. Li, Y.; Liu, H.; Wang, K.; Chen, K. Research on cavitation induced noise feature of marine centrifugal pump under various cavitation numbers. Water Resour. Power 2017, 35, 162-165. (In Chinese)

30. Lu, J.; Yuan, S.; Yuan, J. Research on the noise induced by cavitation under the asymmetric cavitation condition in a centrifugal pump. In Proceedings of the 9th International Symposium on Cavitation, Lausanne, Switzerland, 6-10 December 2015.

31. Wang, Y.; Zhao, Y.; Dong, L.; Dai, C.; Liu, H.; Xu, H. Cavitation characteristics of ultra-low specific speed centrifugal pump based on fluid-acoustic coupling method. T. Chin. Soc. Agric. Mach. 2017, 48, 114-123. (In Chinese)

32. Dong, R.; Chu, S.; Katz, J. Effect of Modification to Tongue and Impeller Geometry on Unsteady Flow, Pressure Fluctuations, and Noise in a Centrifugal Pump. J. Turbomach. 1997, 119, 506-515. [CrossRef]

33. Mattia, B.; Emiliano, M. Incipient cavitation detection in external gear pumps by means of vibroacoustic measurements. Measurement 2018, 129, 51-61.

34. Qing, B.; Yu, B.; Lan, W.; Hu, J. Measurement of cavitation noise in centrifugal pump. J. Drain. Irrig. Mach. Eng. 2016, 34, 198-203. (In Chinese) 
35. Valentino, C.; Fabio, B.; Gianfranco, F.; Riccardo, F.; Felice, A.P.; Michele, S. A control system for preventing cavitation of centrifugal pumps. In Proceedings of the 73rd Conference of the Italian Thermal Machines Engineering Association, Pisa, Italy, 12-14 September 2018.

36. Lu, D. Experimental Study on Flow-Noise of Centrifugal Pump in Variable Working Condition. Master's Thesis, Shandong University, Jinan, China, June 2017. (In Chinese)

37. Tu, Y. Hamiton Method and Its Application for Aeroacoustics. Ph.D. Thesis, Huazhong University of Science and Technology, Wuhan, China, May 2013. (In Chinese)

38. Lighthill, M.J. On sound generated aerodynamically. I General theory. Proc. R. Soc. Lond. Ser. A 1952, 211, 564-587.

39. Ffowcs Williams, J.E.; Hawkings, D.L. Sound generation by turbulence and surfaces in arbitrary motion. Philos. Trans. R. Soc. A 1969, 264, 321-342.

40. Ffowcs Williams, J.E.; Hawkings, D.L. Theory relating to the noise of rotating machinery. J. Sound Vib. 1969, 10, 10-21. [CrossRef]

41. Powell, A. Theory of vortex sound. J. Acoust. Soc. Am. 1964, 36, 177-195. [CrossRef]

42. Howe, M.S. Contributions to the theory of aerodynamic sound with application to excess jet noise and the theory of the flute. J. Fluid Mech. 1975, 71, 625-673. [CrossRef]

43. Takaishi, T.; Miyazawa, M.; Kato, C. A computational method of evaluating noncompact sound based on vortex sound theory. J. Acoust. Soc. Am. 2007, 121, 1353-1361. [CrossRef]

44. Schram, C.; Hirschberg, A. Application of vortex sound theory to vortex-pairing noise: Sensitivity to errors in flow data. J. Sound Vib. 2003, 266, 1079-1098. [CrossRef]

45. Liu, Q.; Qi, D.; Tang, H. Computation of aerodynamic noise of centrifugal fan using large eddy simulation approach, acoustic analogy, and vortex sound theory. Proc. Inst. Mech. Eng. Part C J. Mech. Eng. Sci. 2007, 221, 1321-1332. [CrossRef]

46. Zhang, N.; Xie, H.; Wang, X.; Wu, B. Computation of vortical flow and flow induced noise by large eddy simulation with FW-H acoustic analogy and Powell vortex sound theory. J. Hydrodyn. 2016, 28, 255-266. [CrossRef]

47. Hardin, J.C.; Pope, D.S. An acoustic/viscous splitting technique for computational aeroacoustics. Theor. Comp. Fluid. Dyn. 1994, 6, 323-340. [CrossRef]

48. Wen, Z.; Jens, N.S. Comment on the Aeroacoustic Formulation of Hardin and Pope. AIAA J. 1999, 37, 141-143.

49. Langthjem, M.A.; Olhoff, N. A numerical study of flow-induced noise in a two-dimensional centrifugal pump. Part I. Hydrodynamics. J. Fluid Struct. 2004, 19, 349-368. [CrossRef]

50. Langthjem, M.A.; Olhoff, N. A numerical study of flow-induced noise in a two-dimensional centrifugal pump. Part II. Hydroacoustics. J. Fluid Struct. 2004, 19, 369-386. [CrossRef]

51. Tu, J.; Gan, L.; Ma, S.; Zhang, H. Flow Noise Characteristics Analysis of Underwater High-Speed Vehicle Based on LES/FW-H Coupling Model. Acoust. Aust. 2019, 47, 91-104. [CrossRef]

52. Rona, A.; Dosoky, M.F.F.E.I.; Adebayo, D.S. A hybrid RANS model of wing-body junction flow. Eur. J. Mech. B-Fluid 2020, 79, 283-296. [CrossRef]

53. Yuan, S.; Si, Q.; Xue, F.; Yuan, J.; Zhang, J. Numerical calculation of internal flow-induced noise in centrifugal pump volute. J. Drain. Irrig. Mach. Eng. 2011, 29, 93-98. (In Chinese)

54. Zhang, N.; Liu, X.; Gao, B.; Wang, X.; Xia, B. Effects of modifying the blade trailing edge profile on unsteady pressure pulsations and flow structures in a centrifugal pump. Int. J. Heat Fluid Flow 2019, 75, 227-238. [CrossRef]

55. Posa, A.; Lippolis, A. Effect of working conditions and diffuser setting angle on pressure fluctuations within a centrifugal pump. Int. J. Heat Fluid Flow 2019, 75, 44-60. [CrossRef]

56. Yang, J.; Liu, J.; Liu, X.; Xie, T. Numerical Study of Pressure Pulsation of Centrifugal Pumps with the Compressible Mode. J. Therm. Sci. 2019, 28, 106-114. [CrossRef]

57. Chen, J.; Wang, Y.; Liu, H.; Shao, C.; Zhang, X. Internal flow and analysis of its unsteady characteristics in centrifugal pump with ultra-low specific-speed. J. Drain. Irrig. Mach. Eng. 2018, 36, 377-383. (In Chinese)

58. Zhu, Y. Study on Unsteady Vortex Characteristics of Centrifugal Pump Based on DDES Model. Master's Thesis, Lanzhou University of Technology, Lanzhou, China, May 2018. (In Chinese)

59. Yang, Q. Numerical Simulation and Analysis on the Internal Flow in Centrifugal Pump Based on Different Turbulence Models. Master's Thesis, Lanzhou University of Technology, Lanzhou, China, June 2010. (In Chinese) 
60. Wagner, C.A.; Hüttl, T.; Sagaut, P. Large-Eddy Simulation for Acoustics; Cambridge University Press: New York, NY, USA, 2007; pp. 167-232.

61. Liu, H.; Ding, J.; Wang, Y.; Tan, M.; Xu, H. Numerical simulation of hydrodynamic noise in centrifugal pump based on LES. J. Mech. Eng. 2013, 49, 177-183. (In Chinese) [CrossRef]

62. Fu, J.; Wang, Y.; Jin, S.; Li, L. Applicability of LES and DES in fluid dynamic noise prediction. J. Huazhong Univ. Sci. Tech. (Nat. Sci. Ed.) 2015, 43, 66-70. (In Chinese)

63. Lu, F.; Qi, D.; Wang, X.; Zhou, Z.; Zhou, H. A numerical optimization on the vibroacoustics of a centrifugal fan volute. J. Sound Vib. 2012, 331, 2365-2385. [CrossRef]

64. Chen, J.; He, Y.; Gui, L.; Wang, C.; Chen, L.; Li, Y. Aerodynamic noise prediction of a centrifugal fan considering the volute effect using IBEM. Appl. Acoust. 2018, 132, 182-190. [CrossRef]

65. Pan, Y.; Li, Y.; Huang, M.; Liao, Y.; Liang, D. Noise source identification and transmission path optimization for noise reduction of an axial piston pump. Appl. Acoust. 2018, 130, 283-293. [CrossRef]

66. Dong, L.; Dai, C.; Lin, H.; Chen, Y. Noise comparison of centrifugal pump operating in pump and turbine mode. J. Cent. South. Univ. 2018, 25, 2733-2753. [CrossRef]

67. Lu, Y.; Wang, Y.; Wang, X.; Zhu, R.; Qiu, W.; Fang, J. Experimental and simulation methods of flow noise on pipeline oil pumps. J. Drain. Irrig. Mach. Eng. 2017, 35, 645-651. (In Chinese)

68. Si, Q.; Yuan, S.; Yuan, J.; Yang, J. Flow-induced Noise Calculation of Centrifugal Pumps Based on CFD/CA Method. J. Mech. Eng. 2013, 49, 177-184. (In Chinese) [CrossRef]

69. Tan, Y.; Wang, H.; Yang, A.; Wang, Z.; Xu, X. Numerical prediction of hydrodynamic noise for a centrifugal pump. J. Univ. Shanghai Sci. Technol. 2011, 33, 90-94. (In Chinese)

70. Wang, Z.; Yang, A.; Dai, R. Numerical prediction of the flow-induced noise of centrifugal pump. J. Mech. Eng. 2012, 48, 162-167. (In Chinese) [CrossRef]

71. Dai, C.; Kong, F.; Feng, Z.; Bai, Y. Numerical and experimental investigation of flow-induced noise in centrifugal pump as turbine. J. Huazhong Univ. Sci. Tech. (Nat. Sci. Ed.) 2014, 42, 17-21. (In Chinese)

72. Dong, L.; Dai, C.; Kong, F.; Fu, L.; Xia, B. Flow-induced exterior noise characteristics of a centrifugal pump as a turbine and different noise contribution analysis. J. Vib. Shock 2016, 35, 168-174. (In Chinese)

73. Cai, J.; Pan, J.; Andrew, G. Experimental study of the pressure fluctuation around the volute tongue of a centrifugal pump at variable rotating speed. Fluid Mach. 2015, 43, 13-16. (In Chinese)

74. Si, Q.; Yuan, J.; Yuan, S.; Wang, W.; Zhu, L.; Gérard, B. Numerical Investigation of Pressure Fluctuation in Centrifugal Pump Volute Based on SAS Model and Experimental Validation. Adv. Mech. Eng. 2014. [CrossRef]

75. Zhang, N.; Yang, M.; Gao, B.; Li, Z.; Ni, D. Experimental and numerical analysis of unsteady pressure pulsation in a centrifugal pump with slope volute. J. Mech. Sci. Technol. 2015, 29, 4231-4238. [CrossRef]

76. Shi, B.; Wei, J.; Zhang, Y. A novel experimental facility for measuring internal flow of Solid-liquid two-phase flow in a centrifugal pump by PIV. Int. J. Multiphas. Flow 2017, 89, 266-276. [CrossRef]

77. Shi, B.; Wei, J.; Zhang, Y. Phase discrimination and a high accuracy algorithm for PIV image processing of particle-fluid two-phase flow inside high-speed rotating centrifugal slurry pump. Flow Meas. Instrum. 2015, 45, 93-104. [CrossRef]

78. Zhang, N.; Gao, B.; Li, Z.; Ni, D.; Jiang, Q. Unsteady flow structure and its evolution in a low specific speed centrifugal pump measured by PIV. Exp. Therm. Fluid Sci. 2018, 97, 133-144. [CrossRef]

79. Tan, M.; Wang, Y.; Liu, H.; Wu, X.; Wang, K. Effects of number of blades on flow induced noise vibration and noise of centrifugal pumps. J. Drain. Irrig. Mach. Eng. 2012, 30, 131-135. (In Chinese)

80. Liu, H.; Wang, Y.; Yuan, S.; Tan, M. Effects of impeller outlet width on the vibration and noise from centrifugal pumps induced by flow. J. Huazhong Univ. Sci. Tech. (Nat. Sci. Ed.) 2012, 40, 123-127. (In Chinese)

81. Wang, Y.; Liu, H.; Liu, D.; Wang, J.; Wu, X. Effects of vane wrap angle on flow induced vibration and noise of centrifugal pumps. T. Chin. Soc. Agric. Eng. 2013, 29, 72-77. (In Chinese)

82. Wang, Y.; Liu, Q.; Liu, D.; Wang, J.; Tang, X. Analysis of flow induced vibration and noise in centrifugal pumps with different blade inlet incidence angle. Fluid Mach. 2013, 41, 1-4. (In Chinese)

83. Zhou, H.; Mao, Y.; Zhang, Q.; Zhao, C.; Qi, D.; Diao, Q. Vibro-acoustics of a pipeline centrifugal compressor part I. Experimental study. Appl. Acoust. 2018, 131, 112-128. [CrossRef]

84. Yuan, S.; Yang, Y.; Yuan, J.; Luo, Y. Measurement system design of flow-induced noise in centrifugal pumps. Drain. Irrig. Mach. 2009, 27, 10-14. (In Chinese) 
85. Si, Q.; Yuan, S.; Yuan, J. Experimental study on the influence of impeller-tongue gap on the performance and flow-induced noise characteristics of centrifugal pumps. J. Vib. Shock 2016, 35, 164-168. (In Chinese)

86. Wang, H.; Xu, X.; Yang, A.; Wang, F.; Tan, Y. Numerical simulation of flow noise in axial-flow pump. J. Drain. Irrig. Mach. Eng. 2011, 29, 199-203. (In Chinese)

87. Huang, H.; Liu, H.; Wang, Y.; Jiang, L.; Shao, C. Effect of inclined trailing edge of blade on vibration and hydrodynamic noise of marine centrifugal pump. J. Vib. Shock 2015, 34, 195-200. (In Chinese)

88. Liu, H.; Dai, H.; Ding, J.; Tan, M.; Wang, Y.; Huang, H. Numerical and experimental studies of hydraulic noise induced by surface dipole sources in a centrifugal pump. J. Hydrodyn. 2016, 28, 43-51. [CrossRef]

89. Guo, C.; Wang, J.; Gao, M. A Numerical Study on the Distribution and Evolution Characteristics of an Acoustic Field in the Time Domain of a Centrifugal Pump Based on Powell Vortex Sound Theory. Appl. Sci. 2019, 9, 5018. [CrossRef]

90. He, T.; Zhong, R.; Sun, Y. Numerical method on hydrodynamic noise of centrifugal pump. J. Ship Mech. 2012, 16, 449-455. (In Chinese)

91. Dong, L.; Dai, C.; Kong, F.; Fu, L.; Cao, R. Flow-induced Noise Characteristic and Contribution to Interior Noise for Centrifugal Pump as Turbine. J. Mech. Eng. 2016, 52, 184-192. (In Chinese) [CrossRef]

92. Ye, X.; Pei, J.; Li, C.; Liu, Z. Experimental Study on Nosie Characteristics of Centrifugal Pump Based on Near-Field Acoustic Pressure Method. Chin. J. Power Eng. 2013, 33, 375-380. (In Chinese)

93. Guo, C.; Gao, M.; Lu, D.; Guan, H. Experimental Study on Radiation Noise Frequency Characteristics of a Centrifugal Pump with Various Rotational Speeds. Appl. Sci. 2018, 8, 796. [CrossRef]

94. Yang, J.; Yuan, S.; Yuan, J.; Si, Q.; Pei, J. Numerical and Experimental Study on Flow-induced Noise at Blade-passing Frequency in Centrifugal Pumps. Chin. J. Mech. Eng. 2014, 27, 606-614. [CrossRef]

95. Si, Q.; Sheng, G.; Heng, Y.; Cui, Q.; Huang, K. Numerical simulation for flow-induced noise in a centrifugal pump based on Lighthill acoustic analogy theory. J. Vib. Shock 2018, 37, 84-90. (In Chinese)

96. Gao, M.; Dong, P.; Lei, S.; Turan, A. Computational Study of the Noise Radiation in a Centrifugal Pump When Flow Rate Changes. Energies 2017, 10, 221. [CrossRef]

97. Lin, G. Study of Flow Induced Radiated Noise in a Multi-Stage Centrifugal Pump. Master's Thesis, Jiangsu University, Zhenjiang, China, June 2017. (In Chinese)

98. Guo, C.; Gao, M.; Lu, D.; Wang, K. An Experimental Study on the Radiation Noise Characteristics of a Centrifugal Pump with Various Working Conditions. Energies 2017, 10, 2139. [CrossRef]

99. Dong, P.; Gao, M.; Guan, H.; Lu, D.; Song, K.; Sun, F. Numerical simulation for variation law of volute radiated noise in centrifugal pumps under variable rotating speed. J. Vib. Shock 2017, 36, 128-133. (In Chinese)

100. Si, Q.; Wang, B.; Yuan, J.; Huang, K.; Lin, G.; Wang, C. Numerical and Experimental Investigation on Radiated Noise Characteristics of the Multistage Centrifugal Pump. Processes 2019, 7, 793. [CrossRef]

101. Guo, C.; Gao, M.; Wang, J.; Shi, Y.; He, S. The effect of blade outlet angle on the acoustic field distribution characteristics of a centrifugal pump based on Powell vortex sound theory. Appl. Acoust. 2019, 155, 297-308. [CrossRef]

102. Dong, L.; Dai, C.; Kong, F.; Fu, L.; Bai, Y. Impact of blade outlet angle on acoustic of centrifugal pump as turbine. Trans. Chin. Soc. Agric. Eng. 2015, 31, 69-75. (In Chinese)

103. Wang, W. Research on Hydrodynamic Noise of Multistage Centrifugal Pump. Master's Thesis, Jiangsu University, Zhenjiang, China, June 2016. (In Chinese)

104. Liu, H.; Li, Y.; Wang, K.; Liu, Z. Study on radiated noise characteristics of multistage centrifugal pump under fluid excitation. J. Huazhong Univ. Sci. Tech. (Nat. Sci. Ed.) 2017, 45, 92-97. (In Chinese)

105. Guo, R.; Li, R.; Zhang, R.; Song, Q. Characteristic analysis of exterior hydrodynamic noise of jetting centrifugal self-priming pump. J. Huazhong Unv. Sci. Tech. (Nat. Sci. Ed.) 2018, 46, 43-48. (In Chinese)

106. You, C.; Zhang, G.; Wu, X. Numerical simulation study on flow-induced noises of centrifugal pump. Large Electr. Mach. Hydraul. Turbine 2019, 1, 64-68. (In Chinese)

107. Guo, C.; Gao, M. Investigation on the flow-induced noise propagation mechanism of centrifugal pump based on flow and sound fields synergy concept. Manuscript in preparation, 2020.

108. Rzentkowski, G.; Zbroja, S. Experimental characterization of centrifugal pumps as an acoustic source at the bladde-pasing frequency. J. Fluid. Struct. 2000, 14, 529-558. [CrossRef]

109. Rzentkowski, G.; Zbroja, S. Acoustic characterization of a CANDU primary heat transport pump at the blade-passing frequency. Nucl. Eng. Des. 2000, 196, 63-80. [CrossRef] 
110. Ye, J. Research on Optimization of Vibration and Structural Noise of Centrifugal Pump. Master's Thesis, Wuhan University of Technology, Wuhan, China, 2006. (In Chinese)

111. Zhang, J.; Xia, S.; Ye, S.; Xu, B.; Song, W.; Zhu, S.; Tang, H.; Xiang, J. Experimental investigation on the noise reduction of an axial piston pump using free-layer damping material treatment. Appl. Acoust. 2018, 139, 1-7. [CrossRef]

112. Liu, H.; Ding, J.; Dai, H.; Tan, M.; Tang, X. Numerical Research on Hydraulically Generated Vibration and Noise of a Centrifugal Pump Volute with Impeller Outlet Width Variation. Math. Probl. Eng. 2014. [CrossRef]

113. Liu, H.; Ding, J.; Tan, M.; Cui, J.; Wang, Y. Analysis and experimental of centrifugal pump noise based on outlet width of impeller. T. Chin. Soc. Agric. Eng. 2013, 29, 66-73. (In Chinese)

114. Feng, T.; Wang, J.; Wu, R. Research on the influence to the flow noise of centrifugal pumps with different gap between impeller and tongue. Food Mach. 2012, 28, 75-78. (In Chinese)

115. Ma, Z.; Chen, E.; Guo, Y.; Yang, A. Numerical Simulation of the Influence of the Diameter at the Outlet of an Impeller on the Noise Level Induced by the Flow Inside a Centrifugal Pump. J. Eng. Therm. Energ. Power 2016, 31, 93-98. (In Chinese)

116. Lang, D. Influence of Blade Outlet Angle on Flow Induced Noise Inside Centrifugal Pump. Master's Thesis, University of Shanghai for Science and Technology, Shanghai, China, March 2013. (In Chinese)

117. Ding, J.; Liu, H.; Wang, Y.; Tan, M.; Cui, J. Numerical study on the effect of blade outlet angle on centrifugal pump noise. J. Vib. Shock 2014, 33, 122-127. (In Chinese)

118. Huang, J.; Geng, S.; Wu, R.; Liu, K.; Nie, C.; Zhang, H. Comparison of noise characteristics in centrifugal pumps with different types of impellers. Acta Acoust. 2010, 35, 113-118. (In Chinese)

119. Dai, C.; Dong, L.; Kong, F.; Bai, Y.; Xia, B. Noise reduction by actively leaning blades in centrifugal pump as turbine. J. Shanghai Jiaotong Univ. 2016, 50, 575-582. (In Chinese)

120. Wang, Y.; Huang, H.; Liu, H.; Wang, W.; Guo, B. Effect of inclined trailing edge of blade on exterior radiation noise of marine centrifugal pump. J. Drain. Irrig. Mach. Eng. 2015, 33, 104-110. (In Chinese)

121. Lu, W.; Wang, Z.; Wu, W.; Shi, Y.; Zhou, S. Analysis and research of centrifugal pump vibration and noise based on rotate speed and the number of impeller blades. In Proceedings of the 5th International Conference on Mechanical Engineering and Mechanics, Yangzhou, China, 20-22 August 2014.

122. Wang, Y.; Liu, H.; Yuan, S.; Liu, D.; Wang, J. Characteristics of cavitation vibration and noise in centrifugal pumps with different vane wrap angles. J. Drain. Irrig. Mach. Eng. 2013, 31, 390-394. (In Chinese)

123. Wu, D.; Liu, Y.; Li, D.; Zhao, X.; Li, C. Effect of materials on the noise of a water hydraulic pump used in submersible. Ocean Eng. 2017, 131, 107-113. [CrossRef]

124. Zhou, P.; Zhang, Q.; Shuai, Z.; Li, W. Inlet design and its influence on vibration and noise of centrifugal pump. J. Drain. Irrig. Mach. Eng. 2015, 33, 16-20. (In Chinese)

125. Si, Q.; Yuan, J.; Heng, Y.; Yuan, S. Effects of cross-section and cut-water shapes of volute on flow induced noise in centrifugal pumps. J. Drain. Irrig. Mach. Eng. 2015, 33, 209-215. (In Chinese)

126. Zhao, W. The Numerical Simulation of the Flow Noise in the Centrifugal Pump and Noise Optimization. Master's Thesis, Huazhong University of Science and Technology, Wuhan, China, January 2013. (In Chinese)

127. Dai, C. Flow-Induced Noise Characteristics for Centrifugal Pump as Turbine Theoretical, Numerical and Experimental Investigations. Ph.D. Thesis, Jiangsu University, Zhenjiang, China, December 2014. (In Chinese)

128. Lomakin, V.O.; Chaburko, P.S.; Kuleshova, M.S. Multi-criteria optimization of the flow of a centrifugal pump on energy and vibroacoustic characteristics. Procedia Eng. 2017, 176, 476-482. [CrossRef]

129. Luo, B. The Research of Flow-Induced Noise of Underwater Pump and Optimal Design. Master's Thesis, Jiangsu University, Zhenjiang, China, June 2017. (In Chinese)

130. Zhang, J.; Jia, J.; Hu, R.; Wang, Y.; Cao, P. Flow noise of pipeline pump and bionic sound optimization. T. Chin. Soc. Agric. Mach. 2018, 49, 138-145. (In Chinese)

131. Cao, Y.; Ke, H.; Lin, Y.; Zeng, M.; Wang, Q. Investigation on the flow noise propagation mechanism in pipelines of shell-and-tube heat exchangers based on synergy principle of flow and sound fields. Appl. Therm. Eng. 2017, 122, 339-349. [CrossRef]

(C) 2020 by the authors. Licensee MDPI, Basel, Switzerland. This article is an open access article distributed under the terms and conditions of the Creative Commons Attribution (CC BY) license (http://creativecommons.org/licenses/by/4.0/). 